\title{
New Hope for Correctional Officers: An Innovative Program for Reducing Stress and Health Risks
}

\author{
Rollin McCraty - Mike Atkinson - Lee Lipsenthal • \\ Lourdes Arguelles
}

(C) Springer Science+Business Media, LLC 2009

\begin{abstract}
This study investigated the impact of a new stress management program on physiological and psychological stress and health risk factors among 75 correctional officers. The experimental group received training in emotion self-regulation techniques intended to reduce stress and health risk factors. Practice of the techniques was enhanced by heart rate variability feedback, which helped participants learn and sustain use of the self-management tools. Measures of physiological stress included cortisol, DHEA, cholesterol, triglycerides, fasting glucose levels, 10-min resting electrocardiogram, heart rate variability, and blood pressure. Three psychological questionnaires assessed emotional stress and work-related variables. There were significant improvements in the experimental group in cholesterol, glucose, heart rate, blood pressure and positive outlook and significant reductions in overall psychological distress. There were significant increases in productivity, motivation, goal clarity, and perceived support. The mean difference between pre- and post-intervention projected health care costs was calculated to be $\$ 1,179$ per employee per year.
\end{abstract}

Keywords HRV · Heart rate variability - Stress . Correctional officers $\cdot$ Health risk

R. McCraty $(\bowtie) \cdot$ M. Atkinson · L. Lipsenthal

HeartMath Research Center, Institute of HeartMath, 14700 West Park Ave., Boulder Creek, CA 95006, USA

e-mail: rollin@heartmath.org

L. Arguelles

Claremont Graduate University, Claremont, CA, USA

\section{Introduction}

Employers give a range of reasons for implementing health promotion programs. There is a general interest in enhancing the quality of life, lowering health risks, and promoting overall employee well-being (Fronstin 1996). Stress management and health promotion programs are especially relevant in correctional settings, as correctional peace officers are exposed to stress outside the range of usual human experience. Correctional peace officers must cope with a great variety of stressors, both within and outside of their institutional role, since constant exposure to interpersonal violence, negative or confrontational interactions, and a sense of personal endangerment can affect officers on a chronic basis (Burke 1994). Shift schedules that disrupt normal sleep patterns and social life, authoritarian management styles, poor interpersonal relationships with supervisors, interdepartmental politics, lack of adequate planning and resources, lack of promotion and transfer opportunities, lack of autonomy in performing duties, and lack of recognition for work accomplishments have been described as examples of organizational stressors for individuals in this profession (Brown and Campbell 1994; Cooper et al. 1982; Stotland and Pendleton 1989). Chronically stressful emotions related to job dissatisfaction, alienation, and burnout have been associated with depression, psychosomatic symptoms, and other symptoms of pathology and illness in over $90 \%$ of studies that examine these relationships in organizational psychology (Burke and Mikkelsen 2005).

In addition to the operational stressors inherent in police and corrections work, numerous studies have shown that work-related stress has a seriously adverse impact on health and well-being (Chandola et al. 2008; Cooper et al. 1982; Kirkcaldy et al. 1995). For example, a recent study 
evaluated the relationships among work stress, behavioral risk factors, incidence of coronary heart disease, cortisol levels, and metabolic syndrome (e.g., stress-related obesity) in 10,308 London civil servants aged 35-55. The results demonstrated that chronic work stress was significantly associated with coronary heart disease and high rises in cortisol. The authors reported that $32 \%$ of the effect of work stress on coronary heart disease was attributable to its effect on health behaviors and the metabolic syndrome (Chandola et al. 2008). According to a recent article in the "Journal of the American Medical Association" (Cohen et al. 2007), there is a documented link between stress and an increased risk for heart attacks, depression, cancer and the progression of HIV and AIDS. Notably, an accompanying article in the same issue shows that workplace stress may be as bad for your heart as smoking and high cholesterol (Aboa-Eboule et al. 2007).

A comprehensive review of peer-reviewed and published studies examining the financial impact of health promotion programs concluded that there are good correlational data to suggest that high levels of stress, excessive body weight, and multiple risk factors are associated with increased health care costs. This review also concluded that health promotion programs are associated with reduced health care costs (Aldana 2001).

Finally, a review of the Health Enhancement Research Organization (HERO) database reveals a significant association between ten modifiable health risks and health care expenditures (Goetzel et al. 1998).The focus of this study and the central unit of analysis was the individual employee. The study sought to document increased health care expenditures associated with certain health risks at the individual level. It was found that employees at high risk for poor health outcomes had significantly higher expenditures than did employees at lower risk in 7 of 10 risk categories: those who reported themselves as depressed (70\% higher expenditures), at high stress (46\%), with high blood glucose levels (35\%), at extremely high or low body weight $(21 \%)$, with high blood pressure $(12 \%)$, and with a sedentary lifestyle (10\%). Employees with multiple risk profiles for specific disease outcomes had higher expenditures than did those without these profiles for the following diseases: heart disease $(228 \%$ higher expenditures), psychosocial problems (147\%), and stroke $(85 \%)$. The authors concluded that common modifiable health risks are associated with increases in the likelihood of incurring health expenditures and in the magnitude of those expenditures.

Given the significant relationships among work stress, employee health risk, and health care costs, this study undertook to evaluate the impact of a workplace health promotion program that provides tools and techniques to help employees learn how to more effectively regulate the unmanaged emotions that lie at the root of their stress. From a psychophysiological perspective, it is important to appreciate that the external incidents, situations, or events that individuals typically equate with "causing" their stress are actually only triggers of the stress response. In reality, stress is the negative perceptions, feelings, and emotions that are triggered by a perceived challenge or threat, whether real or imagined (McCraty and Tomasino 2006b).These negative perceptual and emotional processes in turn drive a wide range of physiological responses and adaptations, commonly described as aspects of the "stress response" (Barrios-Choplin et al. 1997). Thus, the actual source of the "stress" that people experience consists primarily of internal emotional unrest, such as feelings of frustration, anger, worry, anxiety, fear, insecurity, depression, or resentment. Moreover, it is notable that police and correctional officers deal with a unique form of stress in the chronic state of emotional dissonance which is required by their job, since they must internally cope with such, often intense, negative emotions while maintaining an outward expression of calm and emotional detachment (Zapf et al. 1999). Thus, the intervention program used in this study adopts an emotion-focused perspective on stress reduction and health promotion, training employees in self-regulation skills designed to target stress at its emotional source.

\section{Methods}

The purpose of this research was to evaluate the effectiveness of the Power to Change Performance stress and health risk reduction program developed by the Institute of HeartMath in reducing stress and health risk factors in correctional peace officers.

\section{Predictions}

The two predictions were: (1) Psychological stress can be reduced by providing correctional officers with specific techniques to effectively manage stress as it occurs, and to prepare for upcoming stressful events to help offset and prevent stress reactions before they occur and (2) Reductions in psychological stress will correlate with reductions in measures of heath risk. The specific objective was to determine the psychosocial and physiological impact of an established stress reduction program on reducing stress in correctional officers.

\section{Study Design}

The study used a quasi-experimental field research design with randomly assigned experimental and wait-list control groups. Correctional officers from the Northern California 
Youth Correctional Center in Stockton participated in the study. Volunteers for participation in the study were recruited through posting of flyers at the sites. Institutional Review Board approval for the study was obtained from the Claremont Graduate University Institutional Review Board, which meets all requirements of federal guidelines, 21 CRF 56.

\section{Participants}

Participants were fully informed about the study and signed informed consent forms. One hundred correctional officers were approached with information about the study and a total of 94 participants were actually recruited and completed the baseline assessments. Shortly thereafter, three dropped out of the study due to time conflicts. Two more became trainers for the program and one became a program coordinator, so they did not participate in the study. The participants were not compensated financially for their participation, but they were able to complete assessments and training during paid working hours. The administration supported their employees' participation in the study, but the training and assessment were voluntary.

Once the baseline data were analyzed, the remaining 88 volunteers were stratified into three relative risk groups: high, medium, and low risk using the Adult Treatment Panel III 10-years risk assessment guidelines (Yen et al. 1991; the method for projecting composite health care costs based on individual risk factors, taken from research by Yen et al. 1991, will be discussed in more detail in the "Results" section). Table 1 shows the parameters used to define high risk and the percentage of employees in the study who were designated at risk for each variable at baseline, compared to corresponding percentages in a reference sample of working adults from a large workplace study (Yen et al. 1991). Only those participants who participated in both the pre and post measurements are included in the analysis: $N=75$.

Study participants were then randomly assigned from each risk group to the experimental or wait-list control group, with 44 participants in each. Age and gender were also added to the stratification criteria to insure that both groups had a homogeneous distribution. The mean age of the correctional officers in the experimental group was 39, and the mean age of the correctional officers in the control group was 40. Sixty-nine percent of the experimental group participants were male, and $70 \%$ of the control group participants were male. Additional descriptive statistics on the participants can be found in Table 2 in the "Results" section.
Table 1 High risk criteria and percentage of employees at risk

\begin{tabular}{|c|c|c|c|}
\hline \multirow[t]{2}{*}{ Risk factor } & \multirow[t]{2}{*}{ High-risk criteria } & \multicolumn{2}{|c|}{ Employees $(\%)$} \\
\hline & & $\begin{array}{l}\text { Current } \\
\text { study } \\
(N=75)\end{array}$ & $\begin{array}{l}\text { Reference } \\
\text { group } \\
(N=1,838)\end{array}$ \\
\hline \multicolumn{4}{|l|}{ 1. Lifestyle habits } \\
\hline Smoking & Current smoker & 5 & 34 \\
\hline Physical activity & Rarely/never & 35 & 10 \\
\hline Medication/drug use & Almost every day, sometimes & 5 & 10 \\
\hline Absences due to illness & 5 days or more & 53 & 12 \\
\hline Drinking alcohol & $\begin{array}{l}\text { Ex-drinker or heavy drinker } \\
\quad \text { (more than } 21 \text { drinks per week) }\end{array}$ & 0 & 9 \\
\hline Seatbelt usage & Using seatbelt $25 \%$ of time or less & 2 & 39 \\
\hline \multicolumn{4}{|l|}{ 2. Psychological perceptions } \\
\hline Life satisfaction & Not very satisfied or somewhat satisfied & 8 & 15 \\
\hline Job satisfaction & Strongly disagree or disagree & 25 & 28 \\
\hline Physical health & Fair or poor & 17 & 18 \\
\hline Serious medical problems & Yes & 2 & 21 \\
\hline \multicolumn{4}{|l|}{ 3. Health risks } \\
\hline Systolic blood pressure & $>140 \mathrm{mmHg}$ & 7 & 15 \\
\hline Diastolic blood pressure & $>90 \mathrm{mmHg}$ & 20 & 11 \\
\hline Cholesterol & $240 \mathrm{mg} / \mathrm{dl}$ or greater & 35 & 22 \\
\hline Relative body weight & More than $20 \%$ overweight & 35 & 28 \\
\hline Chronic bronchitis/emphysema & Yes & 0 & 8 \\
\hline Risk age index & $\begin{array}{l}>4.0 \text { Years (difference between } \\
\text { appraised and achievable ages) }\end{array}$ & 83 & 38 \\
\hline
\end{tabular}




\section{Procedure}

The experimental group then participated in the 2-days "Power to Change Performance" program. Approximately 90 days after the experimental group participants had attended the training program, both groups again completed the same stress and health risk assessments. There was some attrition during this 3-months period, and the final summary is based on data from a total of 75 participants (43 experimental and 32 control). Following the completion of the study, the wait-list control group then received the same training program.

\section{Description of Intervention Program}

The "Power to Change Performance" stress reduction program incorporates a series of emotion-refocusing and restructuring techniques developed by the Institute of HeartMath (Boulder Creek, CA). These research-based, positive emotion-focused techniques are designed to reduce stress and negative affect, increase positive affect and selfregulation skills, enhance health, and improve cognitive performance (Childre and Cryer 2000; McCraty et al. 2006). Previous studies have demonstrated that these techniques favorably impact physiological balance by reducing sympathetic arousal, increasing parasympathetic activity (McCraty et al. 1995; Tiller et al. 1996), reducing stress hormone levels (McCraty et al. 1998) and enhancing immune system activity (McCraty et al. 1996; Rein et al. 1995). These techniques have also been shown to impact organizationally relevant outcomes, such as improving productivity, goal clarity, communication, and job satisfaction, and reducing employee turnover (Barrios-Choplin et al. 1997, 1999; Childre and Cryer 2000; McCraty et al. 1991, 2003). In addition, practice of the HeartMath techniques has been demonstrated to improve health status and quality of life in diverse clinical populations. For example, significant blood pressure reductions have been demonstrated in individuals with hypertension (McCraty et al. 2003), improved functional capacity and reduced depression in congestive heart failure patients (Luskin et al. 2002); improved psychological health and quality of life individuals with diabetes (McCraty et al. 2000), and improvements in symptoms in patients with cardiac arrhythmias (McCraty and Tomasino 2006a). In a UK study, increased HRV coherence, enhanced calmness, and improved long-term memory were measured in healthy individuals who used the techniques over a period of 7 weeks (Bradford et al. 2005); see also summary in McCraty et al. (2006). Most recently, the HeartMath techniques coupled with HRV coherence biofeedback technology were found in a large national study to significantly reduce test anxiety, improve highstakes test performance, and improve socioemotional functioning in high school students. Furthermore, a physiological sub-study using HRV measures revealed that students exposed to the intervention not only exhibited the ability to positively modulate their autonomic response to acute stress in real time, but also that through their consistent use of the tools over the study period, these students had instantiated a healthier and more adaptive pattern of psychophysiological functioning as a new, stable baseline or norm (Bradley et al. 2007).

The efficacy of the HeartMath program in a law enforcement setting has previously been demonstrated in a study that examined the impact of a program on police officers from seven different agencies in Santa Clara County, California (McCraty et al. 1999). In that study, heart rate and blood pressure measurements taken during simulated police call scenarios showed that acutely stressful circumstances likely to be encountered on the job result in a tremendous degree of physiological activation from which it takes the body a considerable amount of time to recover. Findings suggested that the HeartMath techniques learned in this study increased participants' calmness, clarity, and focus during these scenarios and enabled the police officers to rapidly and deeply recalibrate, both physiologically and psychologically, after the intense stress was over. Enhanced work performance in the trained group was also noted, as well as improvements in communication skills at work and home. Overall, the results of this investigation provided evidence that the HeartMath program was effective in reducing damaging physiological and psychological responses to both acute and chronic stress in police while positively impacting a variety of major life areas in a relatively short period of time (McCraty et al. 1999).

The positive emotion-based emotion self-regulation techniques provided in the "Power to Change Performance" program are distinguished from other commonly used stress management techniques because they have been shown to induce a system-wide shift to a distinctive mode of optimal psychophysiological function, termed psychophysiological coherence (McCraty et al. 2006). Activated by sustained heartfelt positive emotions and attitudes, the psychophysiological coherence mode is characterized by increased emotional stability, improved cognitive performance, and increased synchronization and harmony in the functioning of the body's physiological systems. The key marker of the coherence mode is the development of a stable, sine-wave-like pattern in the heart rate variability waveform, oscillating at a frequency of $\sim 0.1 \mathrm{~Hz}$; this pattern is called heart rhythm coherence. Heart rhythm coherence is reflected in the HRV power spectrum as an unusually high-amplitude peak in the low frequency band, centered around $0.1 \mathrm{~Hz}$, with no other major peaks in the power spectrum. This indicates vascular system resonance, a shift in autonomic balance toward increased 
parasympathetic activity (see "Discussion" for further explanation), increased synchronization between the two branches of the autonomic nervous system, and entrainment between the heart rhythm pattern, respiration, and blood pressure rhythms (McCraty et al. 2006; Tiller et al. 1996).

Heart rhythm coherence can be quantified by the following method. First, the maximum peak is identified in the $0.04-0.26 \mathrm{~Hz}$ range of the HRV power spectrum (the frequency range within which coherence and entrainment can occur). The peak power is then determined by calculating the integral in a window $0.030 \mathrm{~Hz}$ wide, centered on the highest peak in that region. The total power of the entire spectrum is then calculated. The coherence ratio is formulated as:

$[\text { Peak power } /(\text { total power }- \text { peak power })]^{2}$

This method provides an accurate measure of coherence that allows for the nonlinear nature of the HRV waveform over time.

Although the psychophysiological coherence mode encompasses beneficial aspects of the "relaxation response," (e.g., reduced sympathetic activation and increased parasympathetic activity), it should be noted that this mode is both psychologically and physiologically distinct from a state of relaxation, having a different set of autonomic, cognitive, emotional, and behavioral correlates (see McCraty et al. 2006; McCraty and Tomasino 2006b). Furthermore, while the HeartMath intervention employs heart rhythm coherence biofeedback in conjunction with positive emotion-focused self-regulation techniques to activate the coherence mode, heart rhythm coherence can also be achieved using other HRV biofeedback protocols, such as those reported by Lehrer and colleagues, who use the term "resonance" to describe the target physiological state (Lehrer et al. 2000; Vaschillo et al. 2006). HRV biofeedback has been shown to increase HRV and heart rhythm coherence and to produce positive outcomes in various populations, including clinically significant improvements in asthma (Lehrer et al. 2004), hypertension (McCraty et al. 2003), and depression (Karavidas 2008; Siepmann et al. 2008). This intervention has also been found to augment vagal regulation of heart rate while facilitating psychological adjustment in patients with coronary heart disease (Nolan et al. 2005). Other recent effective applications of HRV biofeedback include reducing test anxiety and improving standardized test performance in high school students (Bradley et al. 2007) and improving cognition in recently returned combat veterans with post-traumatic stress disorder (Ginsberg 2009).

\section{Intervention Program Training Modules}

The "Power to Change Performance" program consisted of five training modules, which were delivered over two consecutive days. More detailed descriptions of the techniques, their conceptual basis, and their applications in organizational settings can be found elsewhere (Childre and Cryer 2000; Childre and Martin 1999; Childre and Rozman 2005).

1. Risk factors: what they are, how to interpret them, and how they relate to health and wellness.

2. Freeze-Frame: Freeze-Frame is a positive emotionrefocusing technique designed specifically to improve decision-making, especially in stressful or challenging situations. The technique is intended to enable individuals to more effectively intervene in the moment that a stress reaction is triggered, and with practice, to offset the harmful or depleting physiological aspects of the stress response. In essence, the technique enables people to consciously disengage from draining negative mental and emotional reactions as they occur and to activate a neutral or positive emotional state before returning to address the stressor from a more emotionally balanced perspective.

3. Coherent communication: enhancing communication, teamwork, and goal clarity. This module includes the Intuitive Listening technique, designed to facilitate clear and constructive communication among people. This technique involves shifting to a heart-coherent state and reestablishing a neutral or appreciative attitude as needed during communication.

4. Power tools for inner quality: creating a caring culture and increasing job satisfaction. The Power to Change Performance intervention is based on the theory that the cumulative effect of many employees self-regulating emotions more effectively and communicating with each other in a more constructive and caring fashion will bring about a positive change in the surrounding organizational culture within which employees work. This module of the program includes the following tools: the Heart Lock-In technique-an emotional restructuring exercise designed to reduce stress and increase psychophysiological coherence; Appreciation-taking time out in one's day to notice and be grateful for the positive aspects of one's life; and Neutral-learning to neutralize distressing emotions.

5. Workplace applications: operationalizing the above tools in an organizational context and applying the key techniques and concepts learned in the program to increase planning and decision-making effectiveness.

The five training modules were augmented by HRV coherence biofeedback training to facilitate learning and effective implementation of the stress reduction techniques. Using a computer-based heart rhythm coherence feedback system (Freeze-Framer; Quantum Intech, Inc., Boulder 
Creek, CA), ${ }^{1}$ participants' heart rate variability patterns (heart rhythms) were displayed in real time as they practiced the self-regulation techniques. This enabled participants to see and feel for themselves how stress and different emotions affect their heart rhythms, and to objectively quantify the favorable shifts in HRV coherence they could achieve by using the techniques. This process also facilitated the learning experience of how to selfactivate a positive emotional shift, which is typically reflected in a more sine wave-like heart rate variability pattern and an increased numerical "coherence ratio" score, or degree of success in one of the technology's interactive modules designed to reinforce and help anchor the self-regulation skills.

During the 3 months following the program, participants were encouraged to practice the stress management tools daily. It was recommended that they do at least five 15-min Heart Lock-Ins and three written Freeze-Frames per week, as well as using the Freeze-Frame technique for $30 \mathrm{~s}$ during each hour at work. Freeze-Framer heart rhythm coherence feedback training systems were made available to experimental group participants, on a shared basis, for use in the workplace and at home. Approximately 8 weeks after the program, all experimental group participants received a follow-up phone call from the program facilitator or study physician in order to answer any questions and discuss any challenges they might be having with the techniques they had learned or lifestyle changes they might wish to make.

\section{Measures}

\section{Health Risk Assessment}

The measures used in the health risk assessment included both a self-report survey and biometric data. The Personal Wellness Profile (PWP; Wellsource, Portland, OR) includes 75 questions pertaining to the following general areas: health information; physical activity; eating practices; alcohol, drugs, and smoking; stress and coping; social health; safety; medical care; and health view. The validity and reliability of these questions have been studied in numerous applications, a review of which was published by Eddington et al. (1999). Additionally, the prediction of future health care cost savings resulting from reductions in the health risks measured by the PWP has been demonstrated based on actual heath care expenditures (Yen et al. 1991). The four primary biometric measures used in the health risk assessment were height, weight, blood pressure,

\footnotetext{
${ }^{1}$ Since this study was conducted, the Freeze-Framer system has been upgraded and renamed the emWave PC.
}

and cholesterol. These measures were collected at the worksite by a licensed nurse. The criteria used to define high risk are based largely on the recommendations of national consensus scientific panels.

\section{Lipid Panel}

The lipid panel included measurements of total cholesterol, high-density lipoprotein (HDL) cholesterol, low-density lipoprotein (LDL) cholesterol, triglycerides, and blood glucose levels. Blood samples were obtained using fingerstick collection and assessed by reflectance photometry (Cholestech-LDX System, Hayward, CA). Blood glucose levels were measured after at least a 9-h fast. A total cholesterol level of $240 \mathrm{mg} / \mathrm{dl}$ or higher was considered a risk factor (National Cholesterol Education Program 2002).

\section{Blood Pressure}

Blood pressure measurements (auscultary method) were made with an instrument that measures the pressure generated by the cuff and the arterial pulsation (DynaPulse, Pulse Metric, San Diego, CA). A total of three blood pressure readings were taken, with a 5-min rest period prior to the first measure and between measures. The average of the three measures was used as the final blood pressure value. Systolic blood pressure $>140 \mathrm{mmHg}$ was considered a risk factor, as was a diastolic blood pressure $>90 \mathrm{mmHg}$.

\section{Autonomic Function: Heart Rate Variability}

Although not used as part of the risk analysis, a 10-min resting electrocardiogram (ECG) was recorded for heart rate variability analysis to provide an assessment of autonomic nervous system function. Heart rate variability (HRV), which is derived from the ECG, is a measure of the naturally occurring beat-to-beat changes in heart rate. The analysis of HRV provides important information relative to the function and activity level of the autonomic nervous system, and decreased HRV is a predictor of future heart disease, increased risk of sudden death, and is correlated with allcause mortality (Dekker et al. 1997; Tsuji et al. 1994, 1996). In this regard, HRV is increasingly being used as a noninvasive screening tool to identify at-risk individuals.

\section{Cortisol, DHEA, and S-IgA: Adrenal Stress Index}

Measurements were also taken of the stress-related hormones cortisol and dehydroepiandrosterone (DHEA), as well secretory immunoglobulin A (S-IgA), a marker of immunity. A number of investigators have proposed the DHEA/cortisol ratio to be an important biological marker of stress and aging (Kerr et al. 1991; Namiki 1994). When 
individuals are under prolonged stress, a divergence in the DHEA/cortisol ratio results (Manolagas et al. 1979). The effects of DHEA/cortisol imbalance can be severe, and may include elevated blood sugar levels, increased bone loss, compromised immune function, decreased skin repair and regeneration, impaired memory and learning, increased fat accumulation, and brain cell destruction (Jabaaij 1993; Kerr et al. 1991; Manolagas et al. 1979; Namiki 1994). S-IgA is the predominant antibody class found in mucosal secretions, which serves as the body's first line of defense against pathogens, and is easily measured noninvasively. To assess levels of cortisol, DHEA, and S-IgA, saliva samples were collected at four time points over a 24-h period (Adrenal Stress Index, Diagnos-Techs, Inc., Kent, WA). Samples were sent to an external reference laboratory for analysis.

\section{Psychological Assessment}

In addition to the psychological scales of the PWP, three other psychological instruments were used in this study. These were included primarily to provide measures of common psychological symptom and behavior patterns associated with emotional stress. Additionally, measures of positive emotions and attitudes, as well as measures relevant to organizational climate and workplace effectiveness were included in this part of the assessment.

\section{Jenkins Activity Survey}

The Jenkins activity survey (JAS; The Highlands, Chapel Hill, NC) is a multiple-choice questionnaire that is designed as a measure of Type A and coronary-prone behavior. Type A behavior patterns are characterized by extremes of competitiveness, striving for achievement and personal recognition, aggressiveness, haste, impatience, and explosiveness and loudness in speech. The JAS yields a composite Type A scale score and three factoranalytically derived subscales: Speed and Impatience, Job Involvement, and Hard-Driving and Competitive. Concurrent validity has been established by comparing JAS scores to Type A ratings based upon a structured interview. Evidence for the predictive validity of the JAS comes primarily from the prospective findings of the Western Collaborative Group Study. Analysis of JAS Type A scores of 2,750 healthy men showed the Type A scale to distinguish the 120 future clinical cases of coronary heart disease from those men who subsequently remained healthy.

\section{Brief Symptom Inventory}

The brief symptom inventory (BSI; National Computer Systems, Minneapolis, MN) is designed to reflect psychological symptom patterns. This 53-item questionnaire contains nine symptom scales (somatization, obsessive-compulsive, interpersonal sensitivity, depression, anxiety, hostility, phobic anxiety, paranoid ideation, and psychoticism) and three global indices (global severity index, positive symptom distress index, and positive symptom total).

\section{Personal and Organizational Quality Assessment}

The personal and organizational quality assessment (POQA; Institute of HeartMath, Boulder Creek, CA) is a questionnaire designed to reflect the key psychological and workplace elements that contribute to organizational climate. The instrument provides a comprehensive assessment in the two main topic areas. Personal scales reflect employees' moods, attitudes, and stress-related symptoms. The stress symptom items possess clinical relevance as valid measures of stress, which can exert a significant negative impact on employee health and work performance. Organizational scales are comprised of questions concerning such areas as strategic understanding, goal clarity and work attitude, job involvement, and factors related to employee behavior, attitudes toward work, and ability to perform well. Standardized scores enable comparisons of the status or performance of an individual or group with that of a relevant reference group.

\section{Results}

\section{Baseline Comparisons}

Tables 2 and 3 show the results of a single factor ANOVA, which was used to compare the baseline physiological and psychological data between the two groups. Taking a conservative approach, differences with a $p$ value $<0.1$ were considered significant. Overall, random distribution was successful in creating equally distributed groups. There were no significant differences between the groups in any of the risk assessment measures. The only significant differences in physiological measures were in S-IgA (an indicator of immunity), with the control group having a higher mean value $(p=0.099)$; and in the HRV measures the RMS-SD (an indicator of parasympathetic function) was lower in the control group ( $p=0.094)$ (Table 2).

In terms of the psychological measures, there were no differences in any scales on the BSI or the JAS. There were differences in the following scales on the POQA: anger $(p=0.04)$, resentfulness $(p=0.056)$, and intention to quit $(p=0.049)$ were greater in the experimental group at baseline, whereas work attitude $(p=0.021)$, manager support $(p=0.003)$, freedom of expression $(p=0.03)$, 
Table 2 Baseline physiological characteristics

\begin{tabular}{|c|c|c|c|}
\hline & \multicolumn{2}{|l|}{ Mean \pm SD } & \multirow[t]{2}{*}{$p<0.1$} \\
\hline & Experimental group $(N=43)$ & Control group $(N=32)$ & \\
\hline Age, years & $39.47 \pm 7.70$ & $40.72 \pm 8.12$ & NS \\
\hline Gender, $\%$ male & 67 & 69 & NS \\
\hline Height, in. & $68.30 \pm 3.14$ & $67.84 \pm 4.28$ & NS \\
\hline Weight, lbs. & $189.84 \pm 33.75$ & $199.03 \pm 49.15$ & NS \\
\hline Body mass index & $28.44 \pm 3.54$ & $30.12 \pm 5.51$ & NS \\
\hline Cholesterol lowering medication status, $\%$ taking drugs & 4.80 & 13.30 & NS \\
\hline Triglycerides, mg/dl & $149.07 \pm 71.07$ & $155.37 \pm 68.73$ & NS \\
\hline Total cholesterol, mg/dl & $217.45 \pm 40.56$ & $220.27 \pm 38.08$ & NS \\
\hline HDL cholesterol, mg/dl & $43.08 \pm 10.06$ & $46.11 \pm 8.23$ & NS \\
\hline LDL cholesterol, mg/dl & $148.98 \pm 40.30$ & $140.27 \pm 36.56$ & NS \\
\hline Total cholesterol/HDL ratio & $5.39 \pm 1.58$ & $4.82 \pm 1.33$ & NS \\
\hline Glucose, mg/dl & $103.00 \pm 21.39$ & $103.13 \pm 16.23$ & NS \\
\hline Cortisol burden, $\mathrm{nM}$ & $30.94 \pm 9.99$ & $31.36 \pm 11.67$ & NS \\
\hline DHEA, ng/ml & $5.11 \pm 2.09$ & $5.14 \pm 2.03$ & NS \\
\hline $\mathrm{S}-\mathrm{IgA}, \mathrm{U} / \mathrm{ml}$ & $11.25 \pm 5.58$ & $15.24 \pm 12.32$ & $*$ \\
\hline Antihypertensive medication status, $\%$ taking drugs & 7.30 & 20 & \\
\hline Systolic blood pressure, $\mathrm{mmHg}$ & $122.39 \pm 13.33$ & $121.26 \pm 11.08$ & NS \\
\hline Diastolic blood pressure, $\mathrm{mmHg}$ & $80.75 \pm 9.55$ & $81.69 \pm 8.76$ & NS \\
\hline Mean arterial pressure, $\mathrm{mmHg}$ & $92.79 \pm 10.32$ & $92.68 \pm 9.11$ & NS \\
\hline Heart rate, BPM & $71.23 \pm 10.89$ & $73.23 \pm 12.72$ & NS \\
\hline Interbeat interval, ms & $867.69 \pm 144.36$ & $843.56 \pm 128.83$ & NS \\
\hline Standard deviation of RR intervals, ms & $59.31 \pm 26.59$ & $49.74 \pm 22.71$ & NS \\
\hline RMS-SD, ms & $38.20 \pm 28.90$ & $26.97 \pm 13.71$ & - \\
\hline Ln(RMS-SD) & $3.42 \pm 0.66$ & $3.15 \pm 0.58$ & $*$ \\
\hline High frequency, $\mathrm{ms}^{2} / \mathrm{Hz}$ & $192.36 \pm 296.43$ & $82.93 \pm 67.93$ & - \\
\hline Ln(high frequency) & $4.40 \pm 1.34$ & $3.95 \pm 1.21$ & NS \\
\hline Low frequency, $\mathrm{ms}^{2} / \mathrm{Hz}$ & $398.15 \pm 383.12$ & $357.17 \pm 407.99$ & - \\
\hline Ln(low frequency) & $5.60 \pm 0.93$ & $5.33 \pm 1.16$ & NS \\
\hline Very low frequency, $\mathrm{ms}^{2} / \mathrm{Hz}$ & $620.50 \pm 626.39$ & $513.84 \pm 631.15$ & - \\
\hline $\operatorname{Ln}$ (very low frequency) & $6.04 \pm 0.89$ & $5.69 \pm 1.07$ & NS \\
\hline Total power, $\mathrm{ms}^{2} / \mathrm{Hz}$ & $1277.83 \pm 1138.74$ & $1011.72 \pm 1016.59$ & - \\
\hline Ln(total power) & $6.79 \pm 0.90$ & $6.45 \pm 1.05$ & NS \\
\hline Low frequency/high frequency ratio & $4.84 \pm 4.21$ & $5.01 \pm 3.37$ & - \\
\hline $\operatorname{Ln}($ low frequency/high frequency ratio) & $1.20 \pm 0.92$ & $1.38 \pm 0.72$ & NS \\
\hline
\end{tabular}

$* p<0.1$

and confidence in the organization $(p=0.006)$ were greater in the control group (Table 3).

\section{Comparison of Baseline Values to Reference Values}

For comparisons to the general working population, pooled baseline data were compared to the norms established by authors of the individual psychometric surveys as well as to established normal ranges for the physiological data. Table 1 shows the percentage of officers with each risk factor and the expected percentage for each risk factor based on data from a reference group of working adults. For lifestyle habits, the correctional officers were under-active in terms of physical activity (35 vs. 10\%) and had a higher percentage of absences due to illness (53 vs. 12\%). In the health risks category the officers had almost twice the percentage of a diastolic blood pressure over $90 \mathrm{mmHg}$ than would be expected (20 vs. 11\%), a higher percentage of employees with cholesterol levels of $240 \mathrm{mg} / \mathrm{dl}$ or greater (35 vs. $22 \%$ ), and more than $20 \%$ overweight (35 vs. $28 \%$ ). The risk age index, which is calculated from the difference between appraised and achievable ages projected by the health risk assessment, indicated that $83 \%$ of the 
Table 3 Baseline psychological characteristics
Mean \pm SD

$p<0.1$

$\overline{\text { Experimental group }(N=41) \quad \text { Control group }(N=28)}$

\begin{tabular}{|c|c|c|c|}
\hline \multicolumn{4}{|c|}{ Personal and organizational quality assessment (POQA) } \\
\hline Positive outlook & $4.92 \pm 1.02$ & $5.02 \pm 1.17$ & NS \\
\hline Gratitude & $4.68 \pm 1.14$ & $4.99 \pm 1.34$ & NS \\
\hline Motivation & $4.23 \pm 1.04$ & $4.46 \pm 1.27$ & NS \\
\hline Calmness & $4.11 \pm 0.94$ & $4.15 \pm 1.02$ & NS \\
\hline Fatigue & $3.07 \pm 1.06$ & $2.90 \pm 1.18$ & NS \\
\hline Anxiety & $2.67 \pm 0.92$ & $2.45 \pm 0.53$ & NS \\
\hline Depression & $1.88 \pm 0.90$ & $1.74 \pm 0.86$ & NS \\
\hline Anger & $2.05 \pm 0.63$ & $1.74 \pm 0.52$ & * \\
\hline Resentfulness & $2.45 \pm 0.69$ & $2.14 \pm 0.55$ & * \\
\hline Stress symptoms & $2.78 \pm 0.97$ & $2.60 \pm 0.84$ & NS \\
\hline Work attitude & $5.18 \pm 1.03$ & $5.77 \pm 0.93$ & * \\
\hline Strategic understanding & $3.96 \pm 1.05$ & $4.23 \pm 1.26$ & NS \\
\hline Manager support & $4.98 \pm 1.18$ & $5.81 \pm 0.92$ & $*$ \\
\hline Goal clarity & $4.59 \pm 1.28$ & $4.95 \pm 1.15$ & NS \\
\hline Job challenge & $5.30 \pm 0.94$ & $5.40 \pm 1.33$ & NS \\
\hline Value of contribution & $4.96 \pm 1.06$ & $5.44 \pm 1.42$ & NS \\
\hline Freedom of expression & $4.40 \pm 1.17$ & $5.06 \pm 1.22$ & * \\
\hline Work intensity & $5.00 \pm 1.13$ & $5.21 \pm 0.98$ & NS \\
\hline Productivity & $4.90 \pm 0.79$ & $5.19 \pm 1.11$ & NS \\
\hline Communication effectiveness & $4.34 \pm 1.24$ & $4.46 \pm 1.28$ & NS \\
\hline Confidence in the organization & $3.29 \pm 1.10$ & $4.10 \pm 1.16$ & * \\
\hline Morale issues & $5.01 \pm 1.47$ & $4.67 \pm 1.70$ & NS \\
\hline Time pressure & $4.40 \pm 1.26$ & $4.29 \pm 0.83$ & NS \\
\hline Intention to quit & $2.98 \pm 1.52$ & $2.21 \pm 1.50$ & $*$ \\
\hline \multicolumn{4}{|l|}{ Brief symptom inventory (BSI) } \\
\hline Somatization & $0.37 \pm 0.36$ & $0.34 \pm 0.54$ & NS \\
\hline Obsessive-compulsive & $0.78 \pm 0.56$ & $0.70 \pm 0.67$ & NS \\
\hline Interpersonal sensitivity & $0.49 \pm 0.51$ & $0.49 \pm 0.69$ & NS \\
\hline Depression & $0.38 \pm 0.40$ & $0.35 \pm 0.68$ & NS \\
\hline Anxiety & $0.41 \pm 0.38$ & $0.37 \pm 0.43$ & NS \\
\hline Hostility & $0.51 \pm 0.38$ & $0.41 \pm 0.59$ & NS \\
\hline Phobic anxiety & $0.14 \pm 0.23$ & $0.16 \pm 0.40$ & NS \\
\hline Paranoid ideation & $0.61 \pm 0.55$ & $0.50 \pm 0.41$ & NS \\
\hline Psychoticism & $0.27 \pm 0.39$ & $0.28 \pm 0.63$ & NS \\
\hline Global severity index & $0.44 \pm 0.28$ & $0.40 \pm 0.49$ & NS \\
\hline Positive symptom distress index & $1.26 \pm 0.26$ & $1.23 \pm 0.38$ & NS \\
\hline Positive symptom total & $17.63 \pm 9.46$ & $15.26 \pm 11.59$ & NS \\
\hline \multicolumn{4}{|l|}{ Jenkins activity survey (JAS) } \\
\hline Type A-overall score & $231.39 \pm 70.46$ & $224.93 \pm 84.45$ & NS \\
\hline Speed and impatience & $177.20 \pm 57.12$ & $184.89 \pm 71.68$ & NS \\
\hline Job involvement & $203.00 \pm 40.71$ & $190.79 \pm 38.37$ & NS \\
\hline Hard-driving and competitive & $115.83 \pm 24.43$ & $126.07 \pm 32.03$ & NS \\
\hline
\end{tabular}

correctional officers had this risk factor, compared to only $23 \%$ in the reference group. This index is a key indicator of the overall controllable health risk of the respondent (Yen et al. 1991).
As law enforcement personal are known to under-report stress and stress symptoms (McCraty et al. 1999; McLaren et al. 1998), additional physiological measures that reflect chronic stress were also included in the study, although 
they were not used as part of the risk assessment. In this population of correctional officers, $21 \%$ had elevated cortisol values equal to or $>40 \mathrm{nM}$, the established cut-off value for high cortisol based on a reference database of over 150,000 individuals (Diagnos-Techs, Inc., Kent, WA). This is double the expected number of individuals that would be predicted based on the general population, suggesting that this study sample had high stress levels.

From the heart rate variability analysis of each participant's baseline ECG, eight measures commonly used in risk assessment were calculated. These were:

\section{Interbeat Interval}

Mean interval between successive heart beats; inverse of heart rate.

\section{Standard Deviation of $R-R$ Intervals}

Provides a measure of overall heart rate variability; correlates with total power.

\section{$R M S-S D$}

The root mean square of successive differences between normal heartbeats. Reflects the high frequency (fast) beatto-beat variations in heart rate, which provide an estimate of the parasympathetic regulation of the heart; correlates with high frequency power.

\section{High Frequency Power}

Spectral power in the range between 0.15 and $0.4 \mathrm{~Hz}$; reflects parasympathetic or vagal activity. The power in this band corresponds to heart rate variations related to the respiratory cycle, commonly referred to as respiratory sinus arrhythmia.

\section{Low Frequency Power}

Spectral power in the range between 0.04 and $0.15 \mathrm{~Hz}$; can reflect both sympathetic and parasympathetic activity, especially in short-term recordings. Parasympathetic influences are particularly present when respiration rates are below seven breaths per minute (Tiller et al. 1996) or when an individual takes a deep breath. This region was previously called the "baroreceptor range," as it also reflects baroreceptor activity (Malliani 1995) and at times blood pressure wave activity and vascular system resonance.

\section{Very Low Frequency Power}

Spectral power in the range between 0.0033 and $0.04 \mathrm{~Hz}$; primarily an index of sympathetic activity. Reduced power in the very low frequency band has been shown to have a stronger association with all-cause mortality than the low frequency and high frequency bands. In addition, low power in the very low frequency band has been shown to be associated with arrhythmically mediated death (Bigger et al. 1992).

\section{Total Power}

Reflects the power in all frequency ranges. Most of the power in this measure derives from the very low frequency band.

\section{Low Frequency/High Frequency Ratio}

Ratio between low frequency and high frequency power. This ratio is sometimes used (primarily in 24-h recordings) to provide a measurement of the relative activity levels of the sympathetic and parasympathetic systems, with a higher number indicating increased sympathetic or reduced parasympathetic activity; however, in some cases this interpretation is misleading, as parasympathetic activity also contributes to power in the low frequency band under certain conditions (see "Discussion" for further elaboration). For a more detailed explanation of the above measures and their clinical relevance, see the HRV Task Force Report (Task Force of the European Society of Cardiology and the North American Society of Pacing and Electrophysiology 1996).

Of the officers whose HRV were analyzed, $8 \%$ were considered to be at increased risk for sudden cardiac death (Singer et al. 1988; Villareal et al. 2002). Furthermore, from the analysis of the ECG, one officer was identified as having significant ECG abnormalities. As this officer also had high triglycerides and other symptoms, it is highly likely that this condition would have led to a heart attack. This individual and his physician were immediately contacted by the study's physician, who was able to insure that the individual was evaluated, treated, and stabilized.

\section{Between-group Comparisons}

The results of an ANCOVA analysis performed to compare pre-post changes between the experimental and control groups showed no significant differences on either the physiological or psychological measures. This is likely due to the fact that the total number of participants in the study was too low to provide the statistical power required to detect between-group differences. Due to budgetary constraints and cutbacks, the number of participants originally intended to be recruited into the study was reduced by twothirds. In addition, the control group exhibited directional improvements in a variety of the physiological and 
psychological measures, which contributed to the lack of significant differences in the between-group analysis.

Based on observations and reports from the worksite, a cross-contamination effect between the experimental and control groups was suspected to have contributed to the directional improvements observed in the control group. To test for the presence of such an effect, a post-study survey, conducted via a telephone interview, was administered to all control group participants. This survey included questions to determine whether control group participants had been exposed to information about the content of the "Power to Change Performance" program through interactions with colleagues in the experimental group, or if their own behavior had been influenced by health- and stress-related behavioral changes that had been made by their experimental group colleagues following their training. Several questions were also included to assess other potential factors that might have contributed to the improvements observed in the control group.

The results of this survey provided clear evidence of a cross-contamination effect between the experimental and control groups. For example, 55\% of the control group participants reported having knowledge of the "Power to Change Performance" program content. Forty-five percent stated that discussing changes their co-workers had made to their diet, exercise, or the way they handled stress had in turn motivated them to make similar changes. It was found that in two separate cases spouses had been assigned, respectively, to the training and control groups. There were also cases where managers who had attended the training program supervised employees in the control group.

The survey results also suggested that the training of the experimental group resulted in improvements in the overall organizational climate that were noticed by and influenced control group participants on a day-to-day basis. For example, $55 \%$ of the control group participants felt that their co-workers who had attended the program were noticeably less stressed. There was clearly an enthusiasm about the program that permeated the environment, as $100 \%$ of the control group participants reported that their co-workers had indicated that the program was benefiting them, and $100 \%$ also stated that they had been looking forward to attending the program.

In addition to cross-contamination issues, the survey revealed that the increased health awareness afforded by the study was also likely a significant factor that inadvertently influenced the improvements in the control group. This is supported by the fact that $84 \%$ of the control group participants reported having been motivated to make changes to their diet and exercise routines as a result of having been made aware of their blood pressure, cholesterol, and other health indicators at the initial data collection point.
In sum, the cross-contamination and motivation effects mentioned above likely combined and reinforced each other in the control group, effectively operating as a methods artifact that reduced the expected pre-post differences between the two groups on the psychological and physiological measures.

\section{Within-group Comparisons}

Due to the issues just noted, pre to post changes for the two groups were analyzed separately. The pre-post changes within each group were analyzed using paired-sample $t$ tests. The results are shown in Tables 4 and 5 and in Figs. 1 and 2.

\section{Analysis of Experimental Group Pre-Post Changes}

The experimental group demonstrated significant pre-post differences in numerous variables tested. In terms of physiological measures, the experimental group participants demonstrated significant reductions in total cholesterol $(p<0.001)$, LDL cholesterol levels $(p<0.001)$, the total cholesterol/HDL ratio $(p<0.001)$, and glucose levels $(p<0.01)$ from pre- to post-training. The Adrenal Stress Index showed a significant reduction in DHEA $(p<0.001)$. The group also exhibited significant changes in a number of cardiovascular variables, including significant reductions in mean arterial pressure $(p<0.001)$ and in both systolic $(p<0.001)$ and diastolic $(p<0.01)$ blood pressure, and a significant reduction in mean heart rate $(p<0.05)$. In measures of heart rate variability/autonomic function, they showed a significant increase in the low frequency/high frequency ratio $(p<0.05)$.

In terms of psychological and work-related measures, on the POQA the experimental group demonstrated significant increases in scales measuring productivity $(p<0.01)$, motivation $(p<0.01)$, goal clarity $(p<0.05)$, perceived manager support $(p<0.05)$, gratitude $(p<0.05)$, and positive outlook $(p<0.05)$, and significant reductions in anger $(p<0.05)$ and fatigue $(p<0.05)$. On the BSI, the group exhibited significant reductions $(p<0.05)$ in hostility, interpersonal sensitivity (feelings of personal inadequacy, inferiority and selfdoubt), paranoid ideation (fearfulness, suspiciousness and mistrust), and the positive symptom total-a measure of overall psychological distress. Finally, the JAS results for the experimental group revealed significant reductions in the global scale measuring the Type A behavior pattern $(p<0.05)$ and in speed and impatience $(p<0.05)$.

\section{Analysis of Control Group Pre-Post Changes}

In terms of physiological measures, the control group showed significant reductions $(p<0.05)$ in total 
Table 4 Pre-post physiological changes

\begin{tabular}{|c|c|c|c|c|c|c|c|c|}
\hline & \multicolumn{4}{|c|}{ Experimental group $(N=43)$} & \multicolumn{4}{|c|}{ Control group $(N=32)$} \\
\hline & \multicolumn{2}{|c|}{ Paired difference } & \multirow[t]{2}{*}{$t$} & \multirow[t]{2}{*}{$p<$} & \multicolumn{2}{|c|}{ Paired difference } & \multirow[t]{2}{*}{$t$} & \multirow[t]{2}{*}{$p<$} \\
\hline & Mean & SD & & & Mean & SD & & \\
\hline Weight, lbs. & -1.52 & 5.68 & 1.76 & NS & -2.17 & 6.27 & 1.96 & NS \\
\hline Body mass index & -0.22 & 0.86 & 1.69 & NS & -0.33 & 0.91 & 2.02 & NS \\
\hline Triglycerides, mg/dl & -12.64 & 44.81 & 1.83 & NS & -6.30 & 48.28 & 0.68 & NS \\
\hline Total cholesterol, mg/dl & -17.73 & 29.61 & 3.79 & 0.001 & -15.33 & 32.18 & 2.61 & 0.05 \\
\hline HDL cholesterol, mg/dl & -0.81 & 3.85 & 1.26 & NS & -1.86 & 4.32 & 2.28 & 0.05 \\
\hline LDL cholesterol, mg/dl & -19.93 & 31.94 & 4.04 & 0.001 & -11.00 & 30.84 & 1.92 & NS \\
\hline Total cholesterol/HDL ratio & -0.52 & 0.88 & 3.84 & 0.001 & -0.05 & 0.84 & 0.35 & NS \\
\hline Glucose, mg/dl & -5.62 & 10.50 & 3.47 & 0.01 & -4.50 & 11.56 & 2.13 & 0.05 \\
\hline Cortisol burden, $\mathrm{nM}$ & -3.45 & 12.14 & 1.33 & NS & -3.45 & 12.14 & 1.33 & NS \\
\hline DHEA, ng/ml & -2.45 & 1.82 & 6.33 & 0.001 & -1.06 & 3.25 & 1.34 & NS \\
\hline $\mathrm{S}-\mathrm{IgA}, \mathrm{U} / \mathrm{ml}$ & 2.68 & 6.54 & -1.92 & NS & -1.06 & 3.25 & 1.34 & NS \\
\hline Systolic blood pressure, $\mathrm{mmHg}$ & -5.74 & 9.06 & 4.06 & 0.001 & -3.34 & 9.13 & 2.00 & NS \\
\hline Diastolic blood pressure, $\mathrm{mmHg}$ & -3.46 & 6.70 & 3.30 & 0.01 & -2.01 & 6.97 & 1.58 & NS \\
\hline Mean arterial pressure, $\mathrm{mmHg}$ & -4.70 & 7.37 & 4.08 & 0.001 & -2.60 & 7.81 & 1.82 & NS \\
\hline Heart rate, BPM & -3.29 & 9.01 & - & - & -4.31 & 10.27 & - & - \\
\hline Interbeat interval, $\mathrm{ms}$ & 38.65 & 106.68 & -2.32 & 0.05 & 44.54 & 118.15 & -1.96 & NS \\
\hline Standard deviation of RR intervals, $\mathrm{ms}$ & -3.53 & 21.25 & 1.06 & NS & 3.99 & 16.07 & -1.29 & NS \\
\hline RMS-SD, ms & -2.37 & 20.19 & - & - & 2.15 & 11.89 & - & - \\
\hline Ln(RMS-SD) & 0.01 & 0.46 & -0.07 & NS & 0.06 & 0.44 & -0.72 & NS \\
\hline High frequency, $\mathrm{ms}^{2} / \mathrm{Hz}$ & -50.46 & 219.31 & - & - & 8.73 & 78.54 & - & - \\
\hline Ln(high frequency) & -0.08 & 0.83 & 0.60 & NS & -0.03 & 0.85 & 0.21 & NS \\
\hline Low frequency, $\mathrm{ms}^{2} / \mathrm{Hz}$ & 75.96 & 280.30 & - & - & 153.37 & 454.43 & - & - \\
\hline Ln(low frequency) & 0.21 & 0.72 & -1.89 & NS & 0.07 & 0.90 & -0.39 & NS \\
\hline Very low frequency, $\mathrm{ms}^{2} / \mathrm{Hz}$ & -6.97 & 903.03 & - & - & 33.19 & 404.76 & - & - \\
\hline Ln(very low frequency) & -0.05 & 0.84 & 0.37 & NS & 0.29 & 0.83 & -1.82 & NS \\
\hline Total power, $\mathrm{ms}^{2} / \mathrm{Hz}$ & -4.75 & 1235.11 & - & - & 192.38 & 774.63 & - & - \\
\hline Ln(total power) & 0.04 & 0.71 & -0.39 & NS & 0.22 & 0.81 & -1.39 & NS \\
\hline Low frequency/high frequency ratio & 2.01 & 4.82 & - & - & 2.03 & 5.38 & - & - \\
\hline $\operatorname{Ln}($ low frequency/high frequency ratio) & 0.29 & 0.82 & -2.27 & 0.05 & 0.10 & 0.62 & -0.86 & NS \\
\hline
\end{tabular}

cholesterol, HDL cholesterol, and glucose levels. No significant differences were observed in measures of heart rate variability/autonomic function. Regarding psychological and work-related measures, the control group showed significant reductions in work attitude $(p<0.01)$ and confidence in the organization $(p<0.05)$, and a significant increase in depression $(p<0.05)$, as measured by the POQA. There were no significant pre-post changes on the BSI or the JAS.

\section{Correlation Analysis}

A correlation analysis was performed separately for each group (at baseline and post-intervention; see "Appendix") to identify patterns of relationships among the 14 psychological measures that were found significant in the paired $t$-tests of pre-post changes. Given that the predicted effects of the intervention are to improve emotional states, work attitudes, and psychosocial disposition in the experimental group, we should expect to observe a pattern of correlations among the psychological measures consistent with these expectations. ${ }^{2}$

Starting first with the baseline results, in broad terms the intervention and control groups have a similar frequency (30 and 31 significant correlations, respectively) and pattern of significant correlations, which, with few exceptions - the 0.404 correlation between Fatigue and Goal Clarity in the intervention group being one-appear consistent with theoretical expectations. One notable

\footnotetext{
2 A full correlation analysis for each group, at baseline and postintervention, of the relationship between the physiological and the psychological variables produced few significant relationships of note and so has not been presented here.
} 
Table 5 Pre-post psychological changes

\begin{tabular}{|c|c|c|c|c|c|c|c|c|}
\hline & \multicolumn{4}{|c|}{ Experimental group $(N=41)$} & \multicolumn{4}{|c|}{ Control group $(N=28)$} \\
\hline & \multicolumn{2}{|c|}{ Paired difference } & \multirow[t]{2}{*}{$t$} & \multirow[t]{2}{*}{$p<$} & \multicolumn{2}{|c|}{ Paired difference } & \multirow[t]{2}{*}{$t$} & \multirow[t]{2}{*}{$p<$} \\
\hline & Mean & SD & & & Mean & SD & & \\
\hline \multicolumn{9}{|c|}{ Personal and organizational quality assessment (POQA) } \\
\hline Positive outlook & 0.33 & 0.89 & -2.33 & 0.05 & -0.01 & 0.83 & 0.08 & NS \\
\hline Gratitude & 0.43 & 1.17 & -2.36 & 0.05 & 0.27 & 1.26 & -1.06 & NS \\
\hline Motivation & 0.43 & 0.82 & -3.38 & 0.01 & 0.13 & 0.91 & -0.70 & NS \\
\hline Calmness & 0.30 & 1.08 & -1.78 & NS & 0.11 & 0.92 & -0.62 & NS \\
\hline Fatigue & -0.37 & 1.16 & 2.03 & 0.05 & -0.11 & 0.96 & 0.56 & NS \\
\hline Anxiety & -0.17 & 0.89 & 1.22 & NS & 0.23 & 0.87 & -1.30 & NS \\
\hline Depression & -0.08 & 0.76 & 0.63 & NS & 0.24 & 0.49 & -2.47 & 0.05 \\
\hline Anger & -0.19 & 0.56 & 2.18 & 0.05 & -0.06 & 0.46 & 0.68 & NS \\
\hline Resentfulness & -0.16 & 0.86 & 1.18 & NS & 0.07 & 0.48 & -0.77 & NS \\
\hline Stress symptoms & -0.23 & 1.02 & 1.42 & NS & -0.04 & 0.58 & 0.38 & NS \\
\hline Work attitude & 0.07 & 0.84 & -0.53 & NS & -0.37 & 0.54 & 3.47 & 0.01 \\
\hline Strategic understanding & -0.09 & 1.12 & 0.53 & NS & 0.03 & 1.16 & -0.14 & NS \\
\hline Manager support & 0.30 & 0.83 & -2.29 & 0.05 & -0.36 & 1.00 & 1.85 & NS \\
\hline Goal clarity & 0.33 & 0.90 & -2.36 & 0.05 & 0.12 & 1.21 & -0.48 & NS \\
\hline Job challenge & -0.17 & 0.77 & 1.46 & NS & -0.29 & 0.97 & 1.55 & NS \\
\hline Value of contribution & 0.02 & 0.95 & -0.11 & NS & -0.05 & 0.95 & 0.28 & NS \\
\hline Freedom of expression & 0.08 & 1.24 & -0.43 & NS & 0.04 & 0.99 & -0.23 & NS \\
\hline Work intensity & 0.16 & 0.82 & -1.26 & NS & 0.08 & 0.78 & -0.50 & NS \\
\hline Productivity & 0.33 & 0.74 & -2.84 & 0.01 & 0.03 & 1.02 & -0.16 & NS \\
\hline Communication effectiveness & 0.29 & 1.22 & -1.54 & NS & 0.42 & 1.41 & -1.49 & NS \\
\hline Confidence in the organization & 0.03 & 1.12 & -0.14 & NS & -0.38 & 0.82 & 2.36 & 0.05 \\
\hline Morale issues & -0.06 & 1.47 & 0.27 & NS & 0.02 & 1.76 & -0.06 & NS \\
\hline Time pressure & -0.20 & 1.08 & 1.21 & NS & -0.13 & 1.28 & 0.54 & NS \\
\hline Intention to quit & -0.04 & 1.49 & 0.16 & NS & 0.23 & 0.94 & -1.25 & NS \\
\hline \multicolumn{9}{|l|}{ Brief symptom inventory (BSI) } \\
\hline Somatization & -0.08 & 0.44 & 1.18 & NS & -0.03 & 0.57 & 0.32 & NS \\
\hline Obsessive-compulsive & -0.17 & 0.55 & 1.95 & NS & -0.05 & 0.73 & 0.38 & NS \\
\hline Interpersonal sensitivity & -0.19 & 0.55 & 2.16 & 0.05 & -0.10 & 0.62 & 0.84 & NS \\
\hline Depression & -0.09 & 0.64 & 0.86 & NS & -0.01 & 0.59 & 0.05 & NS \\
\hline Anxiety & -0.13 & 0.49 & 1.70 & NS & -0.04 & 0.43 & 0.46 & NS \\
\hline Hostility & -0.15 & 0.43 & 2.13 & 0.05 & -0.16 & 0.48 & 1.73 & NS \\
\hline Phobic anxiety & -0.01 & 0.36 & 0.09 & NS & -0.11 & 0.39 & 1.55 & NS \\
\hline Paranoid ideation & -0.17 & 0.50 & 2.19 & 0.05 & -0.01 & 0.41 & 0.16 & NS \\
\hline Psychoticism & -0.04 & 0.38 & 0.67 & NS & 0.00 & 0.51 & 0.02 & NS \\
\hline Global severity index & -0.11 & 0.37 & 1.88 & NS & -0.05 & 0.44 & 0.62 & NS \\
\hline Positive symptom distress index & -0.07 & 0.32 & 1.34 & NS & 0.00 & 0.39 & -0.03 & NS \\
\hline Positive symptom total & -4.53 & 11.11 & 2.57 & 0.05 & -0.67 & 9.20 & 0.38 & NS \\
\hline \multicolumn{9}{|l|}{ Jenkins activity survey (JAS) } \\
\hline Type A-overall score & -14.59 & 45.97 & 2.03 & 0.05 & -13.79 & 52.03 & 1.40 & NS \\
\hline Speed and impatience & -17.90 & 44.05 & 2.60 & 0.05 & -14.61 & 39.86 & 1.94 & NS \\
\hline Job involvement & -5.76 & 31.43 & 1.17 & NS & -8.29 & 29.31 & 1.50 & NS \\
\hline Hard-driving and competitive & -0.71 & 22.79 & 0.20 & NS & -4.89 & 19.88 & 1.30 & NS \\
\hline
\end{tabular}




\section{Experimental Group: Physiological Measures Before and After Intervention}
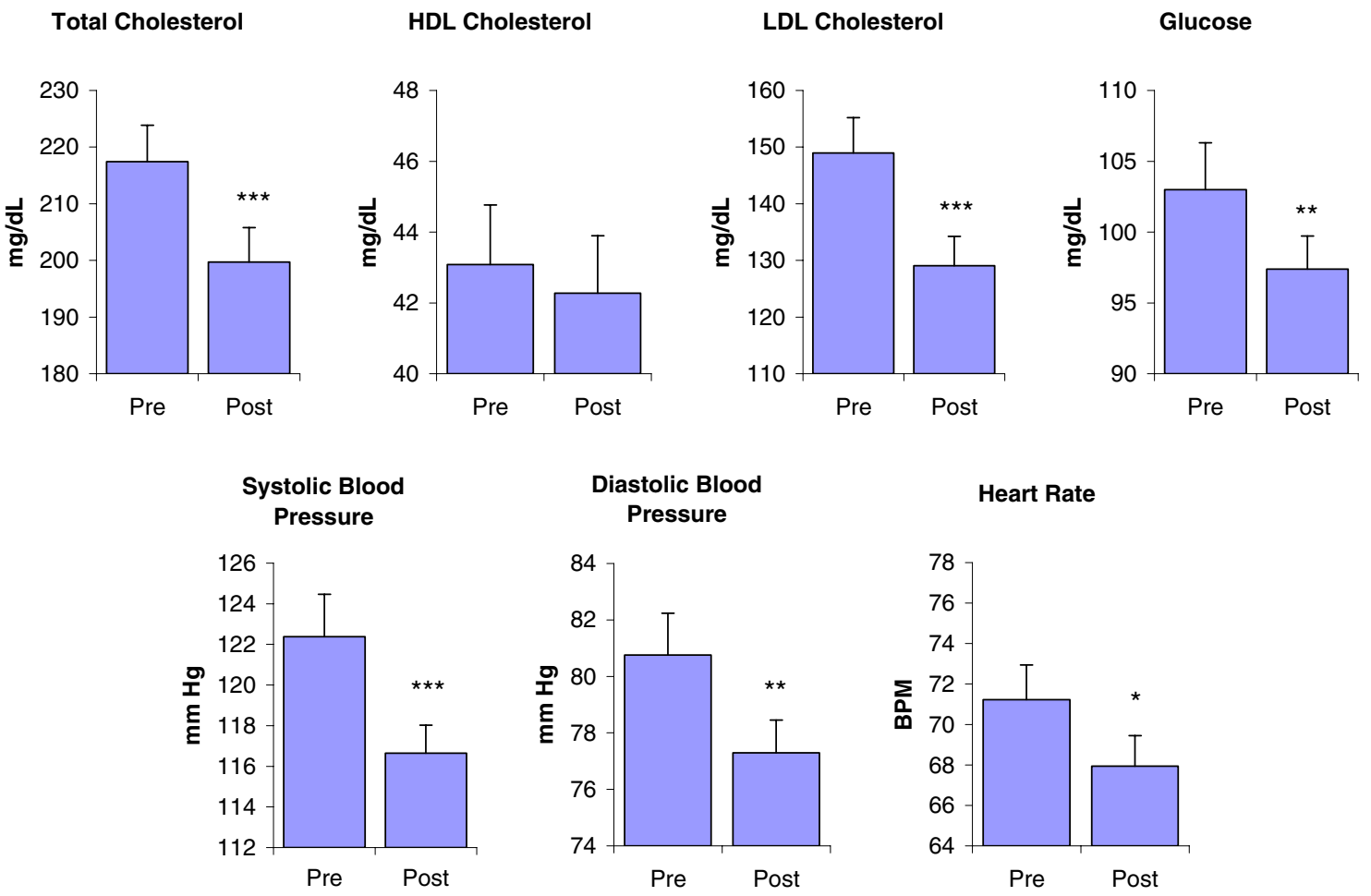

Fig. 1 Physiological measures before and after intervention among participants in experimental group. Bar graphs illustrate physiological variables in the experimental group, measured before and 3 months after the intervention program. The group showed significant reductions in total cholesterol, LDL cholesterol, blood glucose levels, systolic and diastolic blood pressure, and heart rate after the intervention. $* p<0.05, * * p<0.01, * * * p<0.001$

between gratitude and motivation (0.531) shows that strengthened feelings of gratitude and motivation found in the $t$-tests above likely reinforce each other, while the negative correlation between gratitude and depression $(-0.426)$ indicates that strengthened feelings of gratitude appear to mitigate feelings of depression.

The second pattern of note is the post-intervention emergence of significant correlations between the BSI and JAS measures of psychosocial disposition and the POQAwork-related attitudes (only two significant correlations were found pre-intervention, whereas post-intervention ten are observed).

The final pattern we note here is pre to post-intervention incidence of significant correlations involving depression (an increase of seven correlates), productivity (an increase of 5), and gratitude (an increase of 4). Overall, the impression is one of a marked shift in the experimental group toward healthier and more appropriate interrelationships among emotions, psychosocial dispositions, and work attitudes. Whether this shift has also involved a greater conscious understanding of these interrelationships is an important question for future research. 


\section{Control Group: Physiological Measures Before and After Intervention}
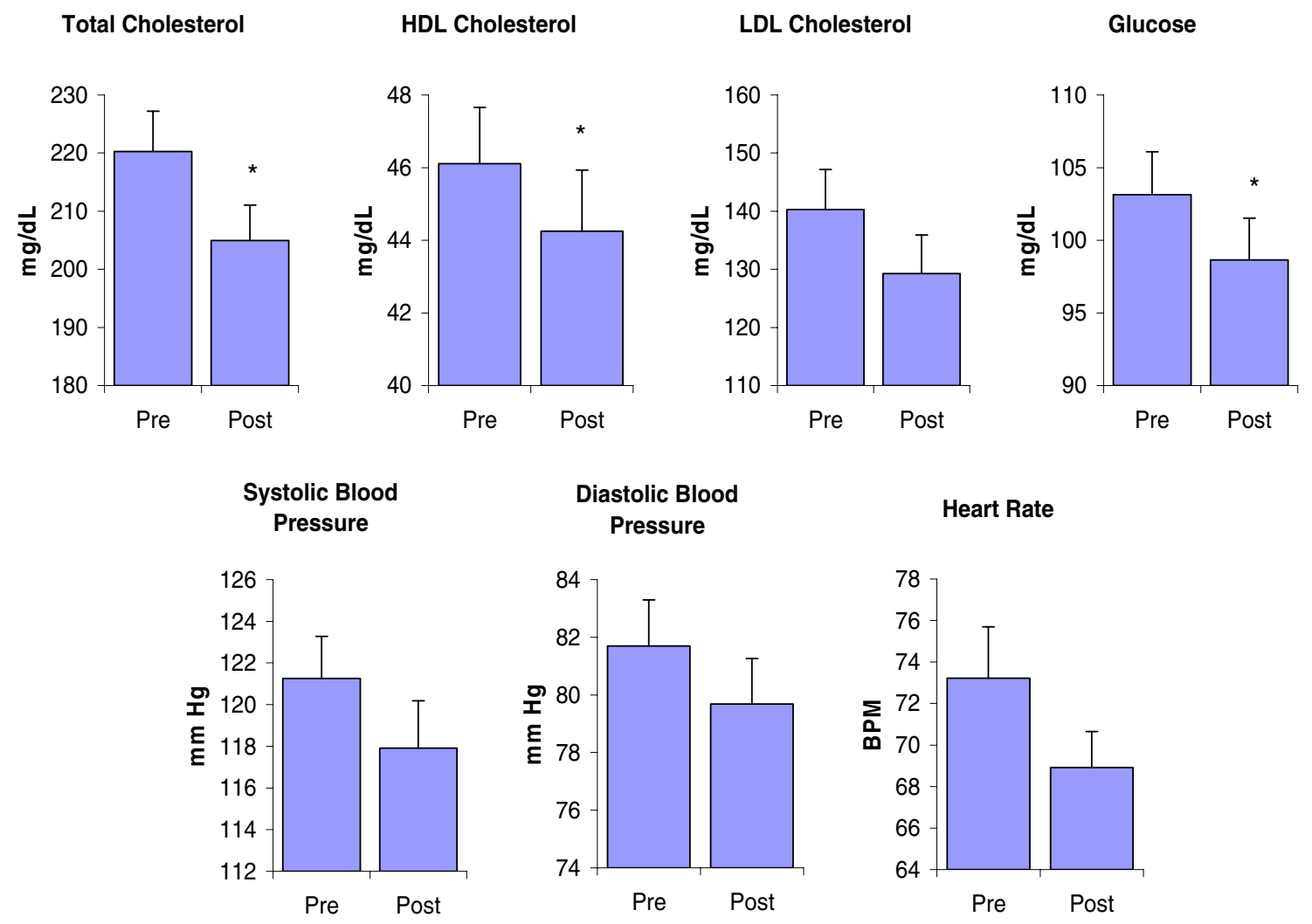

Fig. 2 Physiological measures before and after intervention among participants in control group. Bar graphs illustrate physiological variables in the control group, measured at baseline and 3 months

\section{Program Evaluations}

Written program evaluations completed by all experimental group participants revealed some important insights, both in identifying the most prominent sources of workplace stress and in assessing the intervention's perceived relevance, applicability, and effectiveness in meeting the needs of this population. Issues relating to managing and dealing with staff and co-worker interpersonal relations were most frequently cited as the greatest challenge faced by participants in the workplace, followed closely by dealing with stress after an incident. Overall, the program was rated highly by the great majority of the officers and appears to directly address issues relevant to correctional officers and the goals of the organization. The Intuitive Listening technique, Freeze-Frame technique, and heart rhythm coherence feedback technology were most frequently cited as the aspects of the program that participants found most relevant. On a question asking what aspects of the program they would improve, the most common response was "None," followed by suggestions to increase the duration of the later. The group showed significant reductions in total cholesterol, HDL cholesterol, and blood glucose levels at the 3-months measurement point. $* p<0.05$

training. Finally, in the section of the evaluation that asked officers to express any additional comments or suggestions they might have, the most common recommendation, expressed by the majority of officers who participated, was that the program be provided for all staff.

These findings are corroborated by the results of an analysis of post-study telephone interviews conducted with experimental group participants. Of the twenty participants who were able to be located for interviewing, 19 (95\%) said that they found the program's tools "useful." When asked how often they used the tools, $17(85 \%)$ reported using the tools at least three times a week, of which 11 $(65 \%)$ said they used the tools daily or more often.

\section{Risk Factor Reduction Cost Analysis}

An analysis was performed to determine the projected cost savings to the organization that would likely result from the reduction in participants' health risk factors. Separate calculations were performed to determine projected changes in health care costs and in absentee costs. 


\section{Health Care Costs}

A number of health risk factors have been shown to be associated with higher health care costs (Table 1). The presence of multiple risk factors provides a better prediction of future costs than any single factor (Aldana 2001). Studies by Yen et al. (1991) established annual health care costs associated with multiple risk factors. It was found that annual health care costs for the group with zero health risk factors were only $37 \%$ of average; the group with one risk factor had costs $70 \%$ of average; employees with two or three risk factors had medical costs that were $105 \%$ of average; those with four or five risk factors had medical costs that were at $139 \%$; and those with six or more risk factors had the highest medical costs, at $301 \%$ of average.

In examining the baseline data for the experimental group, it was found that $8 \%$ of this sample had only one risk factor, $49 \%$ had two or three risk factors, $38 \%$ had four or five risk factors and $5 \%$ had six or more risk factors. Of the control group, $13 \%$ had one risk factor, $43 \%$ had two or three risk factors, $39 \%$ had four or five risk factors, and $4 \%$ had six or more. At the completion of the study, $43 \%$ of the experimental group participants had reduced a sufficient number of their risk factors to place them into a lower projected cost status, whereas the percentage of control group participants who lowered their projected cost status was only $26 \%$ (Fig. 3). For both groups these

\section{Impact of Risk Factor Changes on Health Care Cost Status}

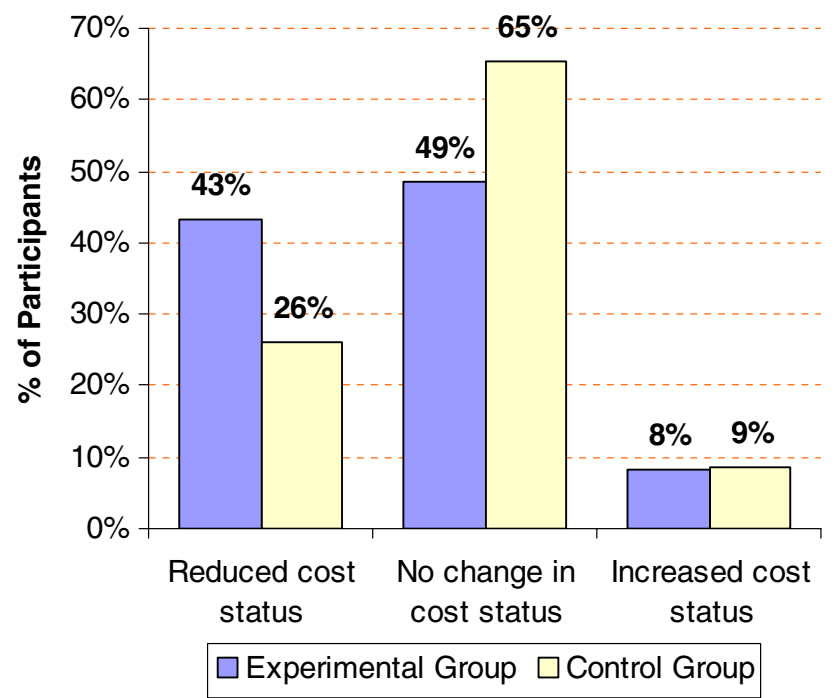

Fig. 3 Impact of risk factor changes on health care cost status. Illustrates changes in health care cost status, based on number of health risk factors in the experimental and control groups over the study period. Reductions in cost status were achieved by $43 \%$ of the experimental group 3 months after the intervention program and by $26 \%$ of the control group over this same time period improvements were primarily due to reductions in cholesterol, diastolic blood pressure, and the risk age index. The experimental group also had risk reduction in systolic blood pressure, and improved life satisfaction and increased regular exercise.

An analysis was performed to calculate the projected health care cost savings that would result from the reduction in risk factors. Because actual annual medical costs were unavailable, we used the US Department of Health and Human Services/Center for Disease Control, National Center for Health Statistics' figure of $\$ 5,219$, the average national health expenditure per capita for 2004 (the most recent year available at the time of the study) to represent the average annual medical cost per employee. By multiplying the average health expenditure by each participant's riskrelated proportion of this cost, the projected health care cost for each participant was determined. For example, a participant with four health risk factors has a projected annual health care cost of $\$ 7,129(\$ 5,129 \times 139 \%=\$ 7,129)$. The mean difference between pre- and post-intervention projected health care costs was calculated for both the experimental and control groups. Using this procedure, a pre-intervention average health care cost of $\$ 6,556$ was projected for each employee in the experimental group. At the end of the study, the projected average health care cost per employee was reduced to $\$ 5,377$, resulting in an average annual savings of $\$ 1,179$ per employee. The control group's pre-intervention projected average health care cost per employee was $\$ 6,381$. At the end of the study, the projected cost per employee was reduced to $\$ 5,995$, resulting in an annual savings of $\$ 386$ per employee.

\section{Discussion}

This study was initiated by the State of California Commission on Correctional Peace Officer Standards and Training (CPOST) to determine if the Power to Change Performance stress and health risk reduction program was an effective intervention to help correctional peace officers reduce the high levels of stress they face on a daily basis; to determine if these officers have increased health risks; and if so, to determine whether these risks could be reduced by this intervention. The physiological measures were considered important aspects of the research, as law enforcement personnel have the tendency to under-report stress levels and stress symptoms (McCraty et al. 1999). It has been suggested by a number of researchers that law enforcement affords a professional environment that encourages emotional detachment from others as well as from workers' own feelings. This may explain officers' tendency to under-report their stress levels (Blackmore 1978; Coman and Evans 1991; Sewell 1981). The repercussions of this clearly extend 
to officers' families, where it is reflected in poor relationships with spouses and children and the notably high rates of marital disruption and divorce known to exist within this profession (Coman and Evans 1991; Jackson and Malasch 1982; Territo and Vetter 1981).

Overall, the emotion self-regulation and communication techniques, together with the HRV biofeedback component of the program, appear to have helped the officers to manage the unavoidable sources of stress they face and to reduce the impact of this stress on their health. The analysis of within-group changes indicated that numerous significant improvements were realized by the implementation of the intervention. The POQA showed significant reductions in fatigue and anger along with increased positive outlook, gratitude, productivity, motivation, goal clarity, and manager support in the experimental group, but not in the control group. The BSI also showed that the experimental group experienced significant reductions in interpersonal sensitivity, hostility, and overall psychological distress, while the JAS showed significant reductions in the global Type A behavior pattern and in speed and impatience.

Physiological measures were also impacted. Total cholesterol and glucose were reduced in both groups, while LDL cholesterol fell in the experimental group. Heart rate, systolic, and diastolic blood pressure were also significantly reduced in the experimental group but not in the control group. We anticipated blood pressure reductions in employees who had elevated blood pressure based on findings from previous studies (Barrios-Choplin et al. 1997; McCraty et al. 2003), however, this study also demonstrated significant reductions in blood pressure in the experimental group as a whole, which supports the perspective that the program reduced the officers' overall stress levels.

The HRV analysis revealed a significant increase in the low frequency/high frequency ratio in the experimental group but not in the control group. It should be noted that while an increase in this ratio is often interpreted to signify an increase in sympathetic activation, a different interpretation is warranted here, in light of the heart rhythm coherence-building intervention used in this study. As mentioned above, the coherence state is marked by entrainment between the heart rhythm, respiration, and blood pressure rhythm at a frequency around $0.1 \mathrm{~Hz}$, which falls in the center of the low frequency band. While this could be misinterpreted as a large increase in sympathetic activity, in reality in this case it is primarily due to an increase in parasympathetic activity and vascular resonance (Tiller et al. 1996). Sophisticated modeling techniques have shown that about $50 \%$ of the total power in the low frequency band is explained by signals impinging on the sinus node which are generated at a central level, and the majority of the remaining power is due to resonance in the arterial pressure regulation feedback loop (Baselli et al.
1994). The sympathetic system does not appear to operate much above frequencies of $0.1 \mathrm{~Hz}$, while the parasympathetic can be observed to operate down to frequencies of $0.05 \mathrm{~Hz}$ (Aguirre et al. 1990). Parasympathetic influences in the low frequency range are particularly present when the respiration rate is below seven breaths per minute, as is true when individuals are in a state of heart rhythm coherence (Tiller et al. 1996). Thus, in this study, the increase in the low frequency/high frequency ratio in experimental group participants most likely reflects an overall increase in heart rhythm coherence and parasympathetic activity facilitated by use of the coherence-building techniques and biofeedback technology. This result is also consistent with the findings that experimental group participants experienced significant increases in gratitude and positive outlook after the training, as positive affective states have been associated both with heart rhythm coherence and with increased power in the low frequency range (McCraty et al. 1995; Tiller et al. 1996; Bacon et al. 2004).

There was a significant decrease in DHEA in the experimental group in this study. One would typically expect a gradual increase in DHEA after a stress reduction intervention (McCraty et al. 1998). The finding that DHEA was decreased in this study sample after the short followup period, combined with the finding that a higher number of officers than would be expected had high baseline levels of cortisol, suggests that these officers are under higher levels of stress than the general population. In the case of a chronically stressed individual, it typically takes between 6 and 9 months for the system to recover (i.e., for cortisol to decrease to normal levels and DHEA to increase); therefore, a longer follow-up period would be required to detect such changes in this study sample.

\section{Limitations and Future Directions}

A main limitation of this study was that the total number of participants was too small to provide the statistical power required to detect between-group differences associated with the intervention program. This, combined with the presence of cross-contamination effects between the two groups, precluded the possibility of a meaningful betweengroup analysis. Use of a matched-group design in which there is no contact between participants in the experimental and control groups would prevent cross-contamination effects and should be employed, if possible, in future follow-up studies. While this would have been an ideal design for the current study, unfortunately it did not prove logistically possible given the available study population. It is unfortunate that the control group was exposed to crosscontamination, which was clearly verified in the post-study questionnaire. On the other hand, it highlighted the desire and enthusiasm the officers had for such a program. 
A further limitation was that beyond the initial group training, participant use of the Freeze-Framer heart rhythm coherence feedback system was not systematically monitored or tracked, partly due to the institutional constraints inherent in conducting field research in a secure correctional facility. The main purpose of the technology in this study was to support participants in the learning and effective use of the emotion self-regulation techniques taught in the program. To this end, units were made available, on a shared basis, for participants to use at their convenience at the work site and to take home. While not directly asked, there is some evidence from post-study interviews that the HRV feedback technology was among the tools many respondents found useful- $40 \%$ named the Freeze-Framer system among the tools that they "used the most." Even so, under ideal conditions, implementing and tracking a systematic practice schedule for all participants would have allowed for a more accurate assessment of the technology's specific contribution to the study's overall outcomes.

Another limitation of the study was its relatively short follow-up period (90 days). Studies with a longer followup period could reasonably be expected to demonstrate additional reductions in health risk factors and increased health care cost savings.

\section{Conclusion}

In conclusion, the results of this study indicate that the "Power to Change Performance" program is a time-efficient and cost-effective means to significantly reduce stress and health risk factors in a population of correctional peace officers, while enhancing employee productivity and psychological well-being. Based on these outcomes, reductions in annual health care costs are projected. In sum, by reducing the physiological, psychological, performancerelated, and financial impact of high stress and health risks in this crucial and demanding profession, the program promises significant benefits both to the employees as individuals and to the organization as a whole. From a broader perspective, the program is likely to prove a valuable stress reduction and health promotion intervention for other high-risk, high-stress professions.

Acknowledgments The research project on which this paper is based, "Impact of the Power to Change Performance Program on Stress and Health Risks in Correctional Officers," was financially supported by the State of California Commission on Correctional Peace Officer Standards and Training (CPOST).

\section{Appendix}

See Table 6.

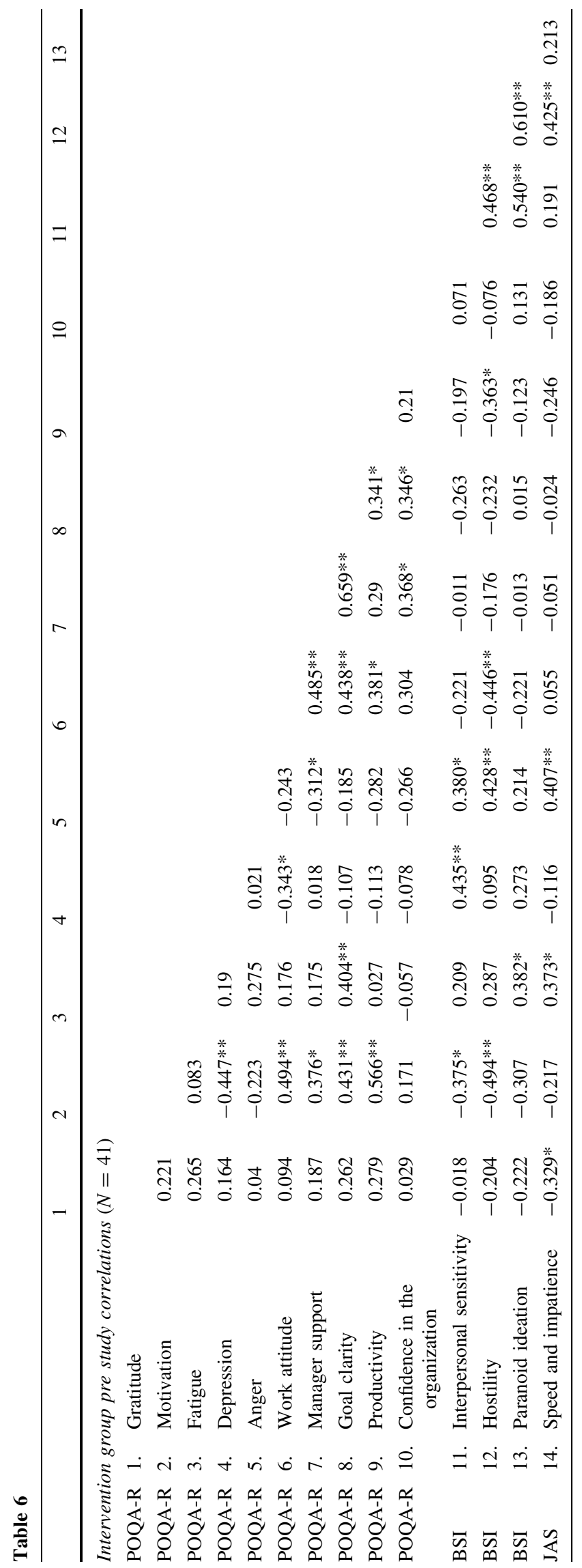




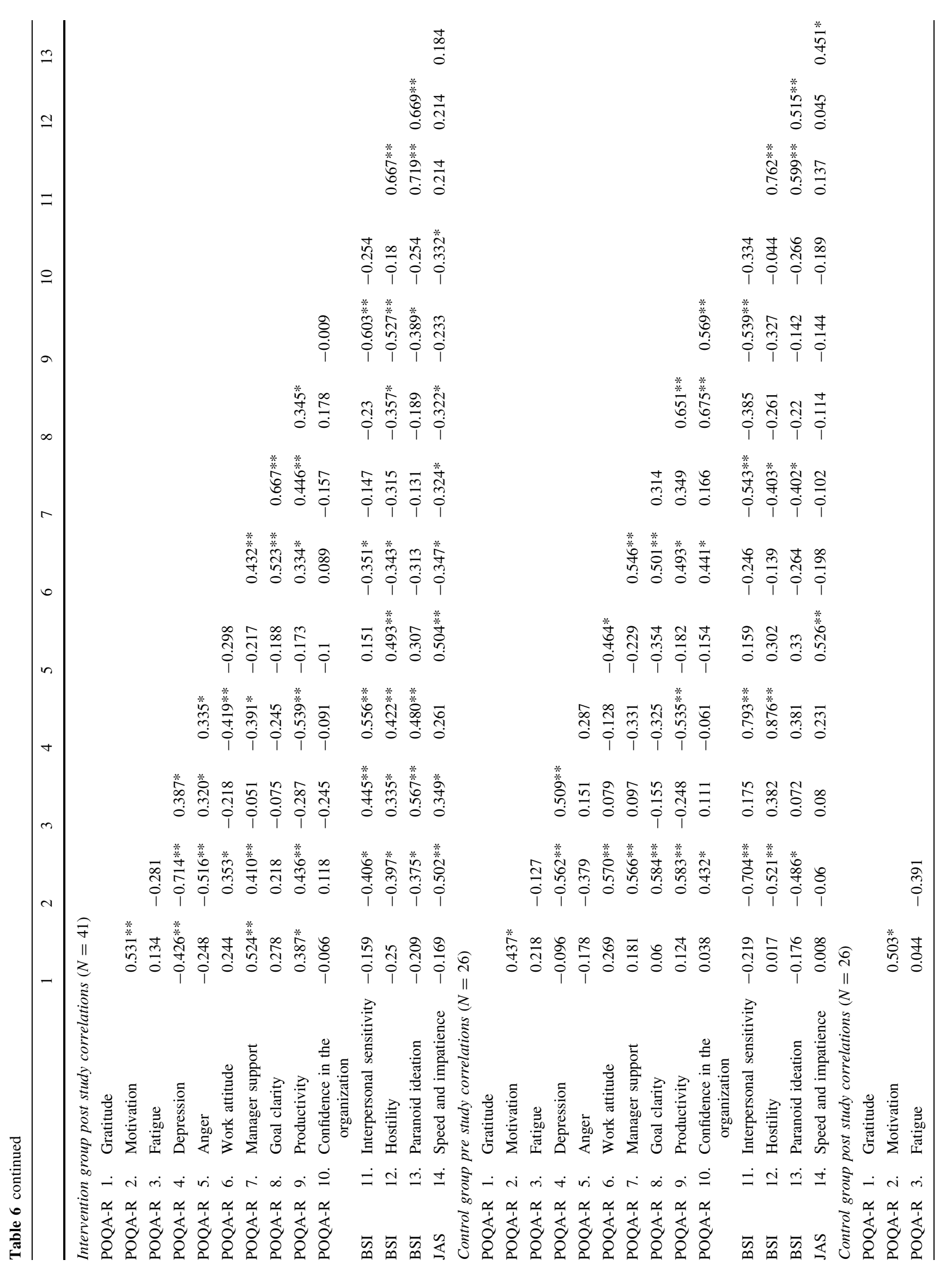




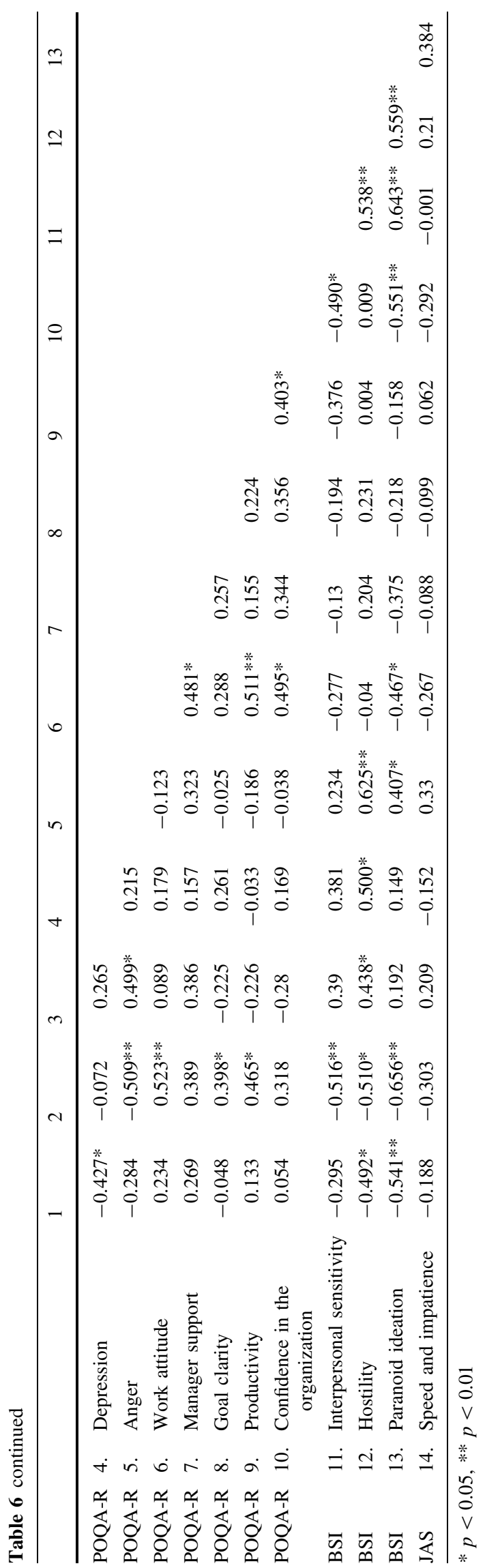

\section{References}

Aboa-Eboule, C., Brisson, C., Maunsell, E., Masse, B., Bourbonnais, R., Vezina, M., et al. (2007). Job strain and risk of acute recurrent coronary heart disease events. Journal of the American Medical Association, 298(14), 1652-1660. doi:10.1001/jama. 298.14.1652.

Aguirre, A., Wodicka, G. R., Maayan, C., \& Shannon, D. C. (1990). Interaction between respiratory and RR interval oscillations at low frequencies. Journal of the Autonomic Nervous System, 29, 241-246. doi:10.1016/0165-1838(90)90150-H.

Aldana, S. G. (2001). Financial impact of health promotion programs: A comprehensive review of the literature. American Journal of Health Promotion, 15(5), 296-320.

Bacon, S. L., Watkins, L. L., Babyak, M., Sherwood, A., Hayano, J., Hinderliter, A. L., et al. (2004). Effects of daily stress on autonomic cardiac control in patients with coronary artery disease. The American Journal of Cardiology, 93(10), 12921294. doi:10.1016/j.amjcard.2004.02.018.

Barrios-Choplin, B., McCraty, R., \& Cryer, B. (1997). An inner quality approach to reducing stress and improving physical and emotional wellbeing at work. Stress Medicine, 13(3), 193-201. doi:10.1002/(SICI)1099-1700(199707)13:3<193::AID-SMI744 $>3.0 . \mathrm{CO} ; 2-\mathrm{I}$.

Barrios-Choplin, B., McCraty, R., Sundram, J., \& Atkinson, M. (1999). The effect of employee self-management training on personal and organizational quality. Boulder Creek, CA: HeartMath Research Center, Institute of HeartMath. publication no. 99-083.

Baselli, G., Cerutti, S., Badilini, F., Biancardi, L., Porta, A., Pagani, M., et al. (1994). Model for the assessment of heart period variability interactions of respiration influences. Medical \& Biological Engineering \& Computing, 32(2), 143-152. doi: 10.1007/BF02518911.

Bigger, J. T., Jr, Fleiss, J. L., Steinman, R. C., Rolnitzky, L. M., Kleiger, R. E., \& Rottman, J. N. (1992). Frequency domain measures of heart period variability and mortality after myocardial infarction. Circulation, 85(1), 164-171.

Blackmore, J. (1978). Are police allowed to have problems of their own? Police Magazine, 1(3), 47-55.

Bradford, E. J., Wesnes, K. A., \& Brett, D. (2005). Effects of peak performance training on cognitive function. Journal of Psychopharmacology (Oxford, England), 19(suppl 5), A44.

Bradley, R. T., McCraty, R., Atkinson, M., Arguelles, L., Rees, R. A., \& Tomasino, D. (2007). Reducing test anxiety and improving test performance in America's schools: Results from the TestEdge national demonstration study. Boulder Creek, CA: HeartMath Research Center, Institute of HeartMath. publication no. 07-09-01.

Brown, J., \& Campbell, E. (1994). Stress and policing: Sources and strategies. Chichester: Wiley.

Burke, R. J. (1994). Stressful events, work-family conflict, coping, psychological burnout, and well-being among police officers. Psychological Reports, 75(2), 787-800.

Burke, R. J., \& Mikkelsen, A. (2005). Career stage and police cynicism. Psychological Reports, $96(3$ pt 2), 989-992.

Chandola, T., Britton, A., Brunner, E., Hemingway, H., Malik, M., Kumari, M., et al. (2008). Work stress and coronary heart disease: What are the mechanisms? European Heart Journal, 29(5), 640-648. doi:10.1093/eurheartj/ehm584.

Childre, D., \& Cryer, B. (2000). From chaos to coherence: The power to change performance. Boulder Creek, CA: Planetary.

Childre, D., \& Martin, H. (1999). The HeartMath solution. San Francisco: HarperSanFrancisco.

Childre, D., \& Rozman, D. (2005). Transforming stress: The HeartMath solution to relieving worry, fatigue, and tension. Oakland, CA: New Harbinger. 
Cohen, S., Janicki-Deverts, D., \& Miller, G. E. (2007). Psychological stress and disease. Journal of the American Medical Association, 298(14), 1685-1687. doi:10.1001/jama.298.14.1685.

Coman, G., \& Evans, B. (1991). Stressors facing Australian police in the 1990s. Policy Studies, 14(4), 153-165.

Cooper, C. L., Davidson, M. J., \& Robinson, P. (1982). Stress in the police service. Journal of Occupational Medicine, 24(1), 30-36.

Dekker, J., Schouten, E. G., Klootwijk, P., Pool, J., Swenne, C. A., \& Kromhout, D. (1997). Heart rate variability from short electrocardiographic recordings predicts mortality from all causes in middle-aged and elderly men. American Journal of Epidemiology, 145(10), 899-908.

Eddington, D., Yen, L., \& Braunstein, A. (1999). The reliability and validity of HRAs. In SPM Handbook of Health Assessment Tools (pp. 135-141). The Society of Prospective Medicine and the Institute for Health and Productivity Management.

Fronstin, P. (1996). Health promotion and disease prevention: A look at demand management programs. EBRI Issue Brief, (177), 1-14.

Ginsberg, J. P. (2009). Autonomic control of heart rate and heart rate variability: Influences on orienting and information processing in combat veterans with PTSD. In D. A. Powell (Ed.), Central nervous system control of learned autonomic adjustments (in press). Kerala, India: Research Signposts.

Goetzel, R. Z., Anderson, D. R., Whitmer, R. W., Ozminkowski, R. J., Dunn, R. L., \& Wasserman, J. (1998). The relationship between modifiable health risks and health care expenditures. An analysis of the multi-employer HERO health risk and cost database. The Health Enhancement Research Organization (HERO) Research Committee. Journal of Occupational and Environmental Medicine, 40(10), 843-854. doi:10.1097/00043764-19981000000003.

Jabaaij, L. (1993). Immunologic, endocrine and psychological influences on cortisol-induced immunoglobulin synthesis in vitro. Psychoneuroendocrinology, 18, 591-605. doi:10.1016/ 0306-4530(93)90036-K.

Jackson, S., \& Malasch, C. (1982). After-effects of job-related stress: Families as victims. Journal of Occupational Behavior, 3, 6377. doi:10.1002/job.4030030106.

Karavidas, M. (2008). Heart rate variability biofeedback for major depression. Biofeedback, 36(1), 18-21.

Kerr, D. S., Campbell, L. W., Applegate, M. D., Brodish, A., \& Landfield, P. W. (1991). Chronic stress-induced acceleration of electrophysiologic and morphometric biomarkers of hippocampal aging. The Journal of Neuroscience, 11(5), 1316-1324.

Kirkcaldy, B., Cooper, C. L., \& Ruffalo, P. (1995). Work stress and health in a sample of U.S. police. Psychological Reports, 76(2), $700-702$.

Lehrer, P. M., Vaschillo, E., \& Vaschillo, B. (2000). Resonant frequency biofeedback training to increase cardiac variability. Rationale and manual for training. Applied Psychophysiology and Biofeedback, 25(3), 177-191. doi:10.1023/A:1009554825745.

Lehrer, P., Vaschillo, E., Vaschillo, B., Lu, S. E., Scardella, A., Siddique, M., et al. (2004). Biofeedback treatment for asthma. Chest, 126(2), 352-361. doi:10.1378/chest.126.2.352.

Luskin, F., Reitz, M., Newell, K., Quinn, T. G., \& Haskell, W. (2002). A controlled pilot study of stress management training of elderly patients with congestive heart failure. Preventive Cardiology, 5(4), 168-172, 176. doi:10.1111/j.1520.037X.2002.01029.x.

Malliani, A. (1995). Association of heart rate variability components with physiological regulatory mechanisms. In M. Malik \& A. J. Camm (Eds.), heart rate variability (pp. 173-188). Armonk, NY: Futura Publishing Company, Inc.

Manolagas, S. C., Anderson, D. C., \& Lindsay, R. (1979). Adrenal steroids and the development of osteoporosis in oophorectomised women. Lancet, 2(8143), 597-600. doi:10.1016/S01406736(79)91663-5.
McCraty, R., Atkinson, M., \& Lipsenthal, L. (2000). Emotional selfregulation program enhances psychological health and quality of life in patients with diabetes. Boulder Creek, CA: HeartMath Research Center, Institute of HeartMath. publication no. 00-006.

McCraty, R., Atkinson, M., Rein, G., \& Watkins, A. D. (1996). Music enhances the effect of positive emotional states on salivary IgA. Stress Medicine, 12(3), 167-175. doi:10.1002/(SICI)1099-1700 (199607)12:3<167::AID-SMI697>3.0.CO;2-2.

McCraty, R., Atkinson, M., Tiller, W. A., Rein, G., \& Watkins, A. D. (1995). The effects of emotions on short-term power spectrum analysis of heart rate variability. The American Journal of Cardiology, 76(14), 1089-1093. doi:10.1016/S0002-9149(99)80309-9.

McCraty, R., Atkinson, M., \& Tomasino, D. (2003). Impact of a workplace stress reduction program on blood pressure and emotional health in hypertensive employees. Journal of Alternative and Complementary Medicine (New York, NY), 9(3), 355369. doi:10.1089/107555303765551589.

McCraty, R., Atkinson, M., Tomasino, D., \& Bradley, R. T. (2006). The coherent heart: Heart-brain interactions, psychophysiological coherence, and the emergence of system-wide order. Boulder Creek, CA: HeartMath Research Center, Institute of HeartMath. publication no. 06-022.

McCraty, R., Barrios-Choplin, B., Rozman, D., Atkinson, M., \& Watkins, A. D. (1998). The impact of a new emotional selfmanagement program on stress, emotions, heart rate variability, DHEA and cortisol. Integrative Physiological and Behavioral Science, 33(2), 151-170. doi:10.1007/BF02688660.

McCraty, R., \& Tomasino, D. (2006a). Coherence-building techniques and heart rhythm coherence feedback: New tools for stress reduction, disease prevention, and rehabilitation. In E. Molinari, A. Compare, \& G. Parati (Eds.), Clinical psychology and heart disease (Vol. 488-509). Milan: Springer.

McCraty, R., \& Tomasino, D. (2006b). Emotional stress, positive emotions, and psychophysiological coherence. In B. B. Arnetz \& R. Ekman (Eds.), Stress in health and disease (pp. 342-365). Weinheim: Wiley-VCH.

McCraty, R., Tomasino, D., Atkinson, M., \& Sundram, J. (1991). Impact of the HeartMath self-management skills program on physiological stress in police officers. Report number, publication no. 99-075. Retrieved from http://www.heartmath.org/ research/research-publications.html.

McCraty, R., Tomasino, D., Atkinson, M., \& Sundram, J. (1999). Impact of the HeartMath self-management skills program on physiological and psychological stress in police officers. Boulder Creek, CA: Heartmath Research Center, Institute of HeartMath. publication no. 99-075.

McLaren, S., Gollan, W., \& Horwell, C. (1998). Perceived stress as a function of occupation. Psychological Reports, 82(3 (Pt 1)), 794.

Namiki, M. (1994). Biological markers of aging. Nippon Ronen Igakkai Zasshi. Japanese Journal of Geriatrics, 31, 85-95.

Nolan, R. P., Kamath, M. V., Floras, J. S., Stanley, J., Pang, C., Picton, P., et al. (2005). Heart rate variability biofeedback as a behavioral neurocardiac intervention to enhance vagal heart rate control. American Heart Journal, 49(6), 1137.e1-1137.e7.

Rein, G., Atkinson, M., \& McCraty, R. (1995). The physiological and psychological effects of compassion and anger. Journal of Advancement in Medicine, 8(2), 87-105.

Sewell, J. (1981). Police stress. In FBI Law enforcement bulletin (pp. 7-11). Washington, DC: Federal Bureau of Investigation.

Siepmann, M., Aykac, V., Unterdorfer, J., Petrowski, K., \& MueckWeymann, M. (2008). A pilot study on the effects of heart rate variability biofeedback in patients with depression and in healthy subjects. Applied Psychophysiology and Biofeedback, 33(4), 195-201.

Singer, D. H., Martin, G. J., Magid, N., Weiss, J. S., Schaas, J. W., Kehoe, R., et al. (1988). Low heart rate variability and sudden 
cardiac death. Journal of Electrocardiology, (Suppl), S46-S55. doi:10.1016/0022-0736(88)90055-6.

Stotland, E., \& Pendleton, M. (1989). Workload, stress, and strain among police officers. Behavioral Medicine (Washington, D.C.), 15(1), 5-17.

Territo, L., \& Vetter, H. (1981). Stress and police personnel. Journal of Police Science and Administration, 9, 195-208.

Tiller, W. A., McCraty, R., \& Atkinson, M. (1996). Cardiac coherence: A new, noninvasive measure of autonomic nervous system order. Alternative Therapies in Health and Medicine, 2(1), 52-65.

Tsuji, H., Larson, M. G., Venditti, F. J. Jr., Manders, E. S., Evans, J. C., Feldman, C. L., et al. (1996). Impact of reduced heart rate variability on risk for cardiac events: The Framingham heart study. Circulation, 94, 2850-2855.

Tsuji, H., Venditti, F. J. Jr., Manders, E. S., Evans, J. C., Larson, M. G., Feldman, C. L., et al. (1994). Reduced heart rate variability and mortality risk in an elderly cohort. The Framingham heart study. Circulation, 90(2), 878-883.

Vaschillo, E. G., Vaschillo, B., \& Lehrer, P. (2006). Characteristics of resonance in heart rate variability stimulated by biofeedback. Applied Psychophysiology and Biofeedback, 31(2), 129-142. doi:10.1007/s10484-006-9009-3.

Villareal, R. P., Liu, B. C., \& Massumi, A. (2002). Heart rate variability and cardiovascular mortality. Current Atherosclerosis Reports, 4(2), 120-127. doi:10.1007/s11883-002-0035-1.

Yen, L. T., Eddington, D. W., \& Witting, P. (1991). Associations between health risk appraisal scores and employee medical claims costs in a manufacturing company. American Journal of Health Promotion, 6(1), 46-54.

Zapf, D., Vogt, C., Seifert, C., Mertini, H., \& Isic, A. (1999). Emotion work as a source of stress: The concept and development of an instrument. European Journal of Work and Organizational Psychology, 8, 371-400. doi:10.1080/135943299398230. 